\section{ECCOMAS}

\section{Proceedia}

COMPDYN 2021

$8^{\text {th }}$ ECCOMAS Thematic Conference on Computational Methods in Structural Dynamics and Earthquake Engineering

M. Papadrakakis, M. Fragiadakis (eds.) Streamed from Athens, Greece, 28 - 30 June 2021

\title{
LINKS OF AESTHETIC VALUE OF MULTI-CURVATURE ARTIFACTS, WITH THEIR STRUCTURAL BEHAVIOR, UTILIZING MACHINE LEARNING ALGORITHMS
}

\author{
Nikolaos P. Bakas ${ }^{1 *}$, Neofytos Christofi ${ }^{2}$, John Bellos ${ }^{2}$, Dimitris Antoniou ${ }^{3}$, George Markou ${ }^{4}$ \\ ${ }^{1}$ Computation-based Science and Technology Research Center, The Cyprus Institute, Nicosia, Cyprus. \\ e-mail:n.bakas@cyi.ac.cy \\ ${ }^{2}$ School of Architecture, Engineering, Land and Environmental Sciences, Neapolis University Pafos, \\ Danais 2, 8042, Pafos, Cyprus. emails: \{n.christofi,j.bellos\}@nup.ac.cy \\ ${ }^{3}$ Department of Architecture, University of Patras, University Campus, 26500 Rio, Patras, Greece, \\ email: antonioud@upatras.gr \\ ${ }^{4}$ Department of Civil Engineering, University of Pretoria, South Africa \\ e-mail: george.markou@up.ac.za
}

\begin{abstract}
In this work, quantitative evidence on whether the aesthetic value of architectural design is associated with its structural response is investigated. The procedure for this study was based on 170 parametric projects, as well as their structural analysis results. The aesthetic value of an architectural project is an ambiguous concept, as it is based on each individual's perception of beauty. This is highlighted in the corresponding literature on parametric design, formfinding, and aesthetics, as well as in an extensive bibliometric analysis of several hundreds of research papers with respect to aesthetics and structures. Henceforth, a questionnaire was developed and given for vote to 23 persons from a variety of disciplines such as architects, engineers, as well as people with profession irrelevant to structures and/or aesthetics. The mean value of the votes of the questionnaire was considered as the dependent variable of the mathematical model, while the structural response parameters, internal forces and nodal displacements, were set as the Independent variables of the model. The obtained data were analyzed with regression analysis, utilizing linear and machine learning models, revealing a significant link between structural response and aesthetics.
\end{abstract}

Keywords: Building Aesthetics, Structural Behaviour, Structural Analysis, Machine Learning, Regression Analysis. 


\section{INTRODUCTION}

Architectural design is highly dependent on structural behaviour and a variety of studies exist in the corresponding literature. Monedero [1] has performed an analysis of the existing literature on parametric design, stating that in the last few years there has been an evolution in technology, while architects have started using it to their advantage. In particular, parametric design is a process of mathematical and programming algorithms, which creates multiple components and operations, assisting the designer to create any complex artifact from simple lines and curves to a composite project which is usually difficult to understand, but it's beautiful aesthetically. By utilizing structural plugins such as Katamba 3D [2]-[6], the creator can investigate the structural analysis results during the architectural design, and change the project so as the structural configuration will be adequate. Shells have been a frequent object of research [7] as it is often seen in nature. Santiago Huerta [8], explains that Gaudi had been using physical models and graphic methods to support his designs. Accordingly, huge columns support the domes of the Sagrada Familia which bring to mind trees. Similarly, by utilizing computer algorithms, Miloš Dimčić [9] demonstrates that by using the same surface and the same number of points, which can be structural objects, you can create a number of different batches that have better structural behaviour than other ordinary objects. Furthermore, at the Post Rotterdam, which has been refurbished [10], the redesign of the building had been done with the aid of Grasshopper3d [3], a software capable for parametric design, in combination with other software in order to find the optimum structural response based on form-finding. The author concludes that these types of tools in design help a lot in finding an ideal figure and furthermore performs excellently in regards to the structural part of the design by making calculations in a short period of time.

In a review paper [11], John S. Gero refers to the fact that after the 19th century, architecture is not considered only as art but also as a science-based on its evolution at its current stage. As a conclusion, he states that architecture combines science that doesn't only create forms and objects but also adjusts them with reference to the human factor in combination with its structural analysis. Natural forms are not drawn or created based on aesthetics but on their structural behaviour in combination with different types of materials [12]. Famous architects like Antonio Gaudi, and to some extend Luigi Nevri and Frei Otto have studied these natural forms in order for them to conclude and create a more natural and organic architecture. The conclusion of this study is that if an architect studies organic designs, he discovers a new world, says the author. To achieve this, one needs a lot of different trials, with different methods, considering environmental issues, materials, engineering and often he refers to pure luck. Michela Turrin [13], refers to the advantages that arise from the parametric design and how easy one can find different forms with the same rationale. She continues by explaining that this is key in the architectural form. Paolo Basso [14] explains that all organic geometric forms that exist are arranged and can be configured based on the NURBS curves, concluding that in the fields of both architecture and engineering new methods need to be found in regards to research, analysis and resolution. The approach of parametric design or other software that use NURBS curves gives the user full control over the smoothness of the object that is being created.

In a statement on Frei Otto [15], Boho Rasch mentions that Frei Otto is fascinated by organic, physical forms (the same happens when we minimize the inclination forces), and lightweight construction. He also states that the architect uses computer-aided means and the vast potential they have in order to specify the shape and behaviour of such organic forms. He concludes that Otto believes in the organic, lightweight form as he believes that it improves the human health and mood, but also nature itself. Renaud Aleis Pierre Emile [16] refers to 
the current tools of design and analysis, as being highly powerful and that they can allow someone to produce and analyze any structural form. However, most of them are not allowed to use such means in the pure design stage of a project. The parametric design allows for a rapid study of complex geometric shapes and can be combined with an algorithmic analysis and optimization to design with performance as a parameter as well as objective. In his conclusions, he states that his work reflects that parametric design can be extended by using ground breaking computer-based ideas in the research for design with an epicenter to perform in creative ways.

Neri Oxman [17], mentions that the recent development of computer-based geometry and the expansion of the CAD software packages that support geometrical model design, combined with the research on design, lead to the evolution of analysis tools. Such tools have now been expanded in order to include complex computerized methods for non-Euclidean geometries, such as the B-spline curves and the NURBS surface. Hence, there will be a new model that studies the form and the implementation of design at the same time. If such an emersion is possible, then this knowledge that computerized geometry offers will be one of the most important forms of disciplined knowledge in computerized design software in architecture. Allen Carlson [18], mentions that aesthetics and nature are directly linked and that the relationship between science and nature is controversial. He also supports the environment and the nature we live in has led us to each one of our own aesthetics. The need of nature is to create something functional and at the same time light [19]; which is a result of constant optimization, that has been going on for millions of years, and which will continue to be as long as this world exists. Accordingly, the concept of form-finding is a process of optimizing the static equilibrium of the structure, finding the corresponding structural form, and architectural synthesis at the same time. The theory of evolution of the species in nature has inspired computer scientists, to develop the so-called evolutionary optimization algorithms [20], [21]. The purpose of this work was to investigate whether the structural behaviour of an architectural artifact is linked with the beauty of the design. It was attained, by utilizing 170 parametric structures, and their structural analysis results, via machine learning techniques.

\section{BIBLIOMETRIC LITERATURE REVIEW}

In order to investigate the literature related to architecture, computational design and structural analysis, the following bibliometric techniques where implemented. Initially, the Google Books database [22], based on 25 million books was searched using Architectural design, parametric design, computational design and form-finding. In Figure 1, it is depicted that in the last few years, and in particular since 1960, more people have begun to look for and learn about parametric design and have also begun to deal with computational design and formfinding as well. Additionally, from Figure 1, it is derived there is a proportion in the world looking for architecture after parametric design and then for form-finding. Interestingly, these are the steps that an architect can follow to design an organic form.

Growth rates of scientific knowledge correspond to a doubling every 9 years [22]. Hence, a vast amount of research papers were investigated with respect to their keywords associations, utilizing a procedure developed in [23], [24]. Figure 2, is the bibliometric map for the keywords of the 1414 documents, obtained from a search in Scopus database [25], comprising the term aesthetics. The frequency of its keyword is indicated with a number before the text, while the size of the corresponding circle is proportional to this frequency. Furthermore, the distances between the circles indicate the number of co-occurrences of these keywords in the papers' database. Utilizing this clustering technique, two major clusters are constructed, one with aesthetics in the center, near with the perception, architecture design and innovation keywords. 


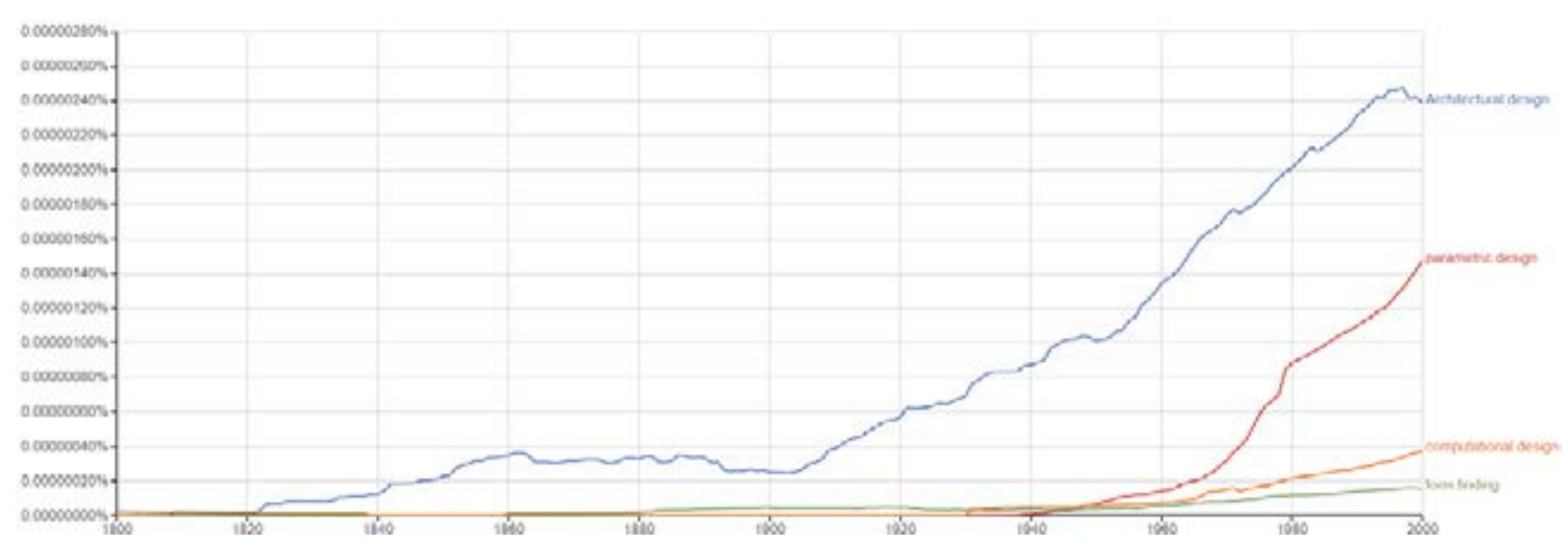

Figure 1: Google Books results of search terms

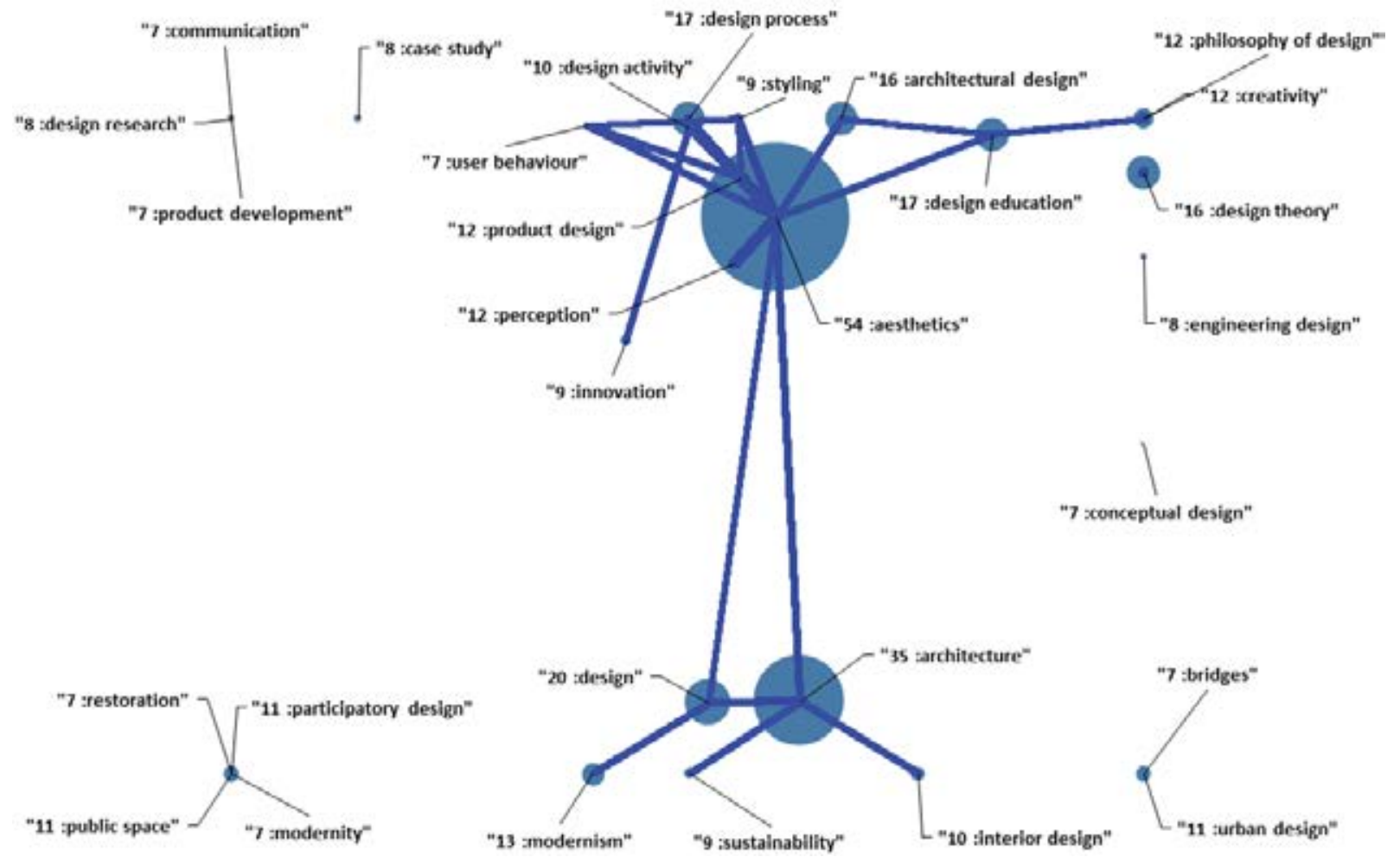

Figure 2: Scopus search for aesthetics

Accordingly, Figure 3, was created, by narrowing the search with the specific keywords of Table 1, as well as limiting the results with the generic keyword stuctur*. Accordingly, tow clusters are developed, one at the bottom left side relative to the engineering literature with keywords structural engineering, engineering design, structural design- and another at the top right region of the map with keywords such as aesthetics, design process, perception etc. 


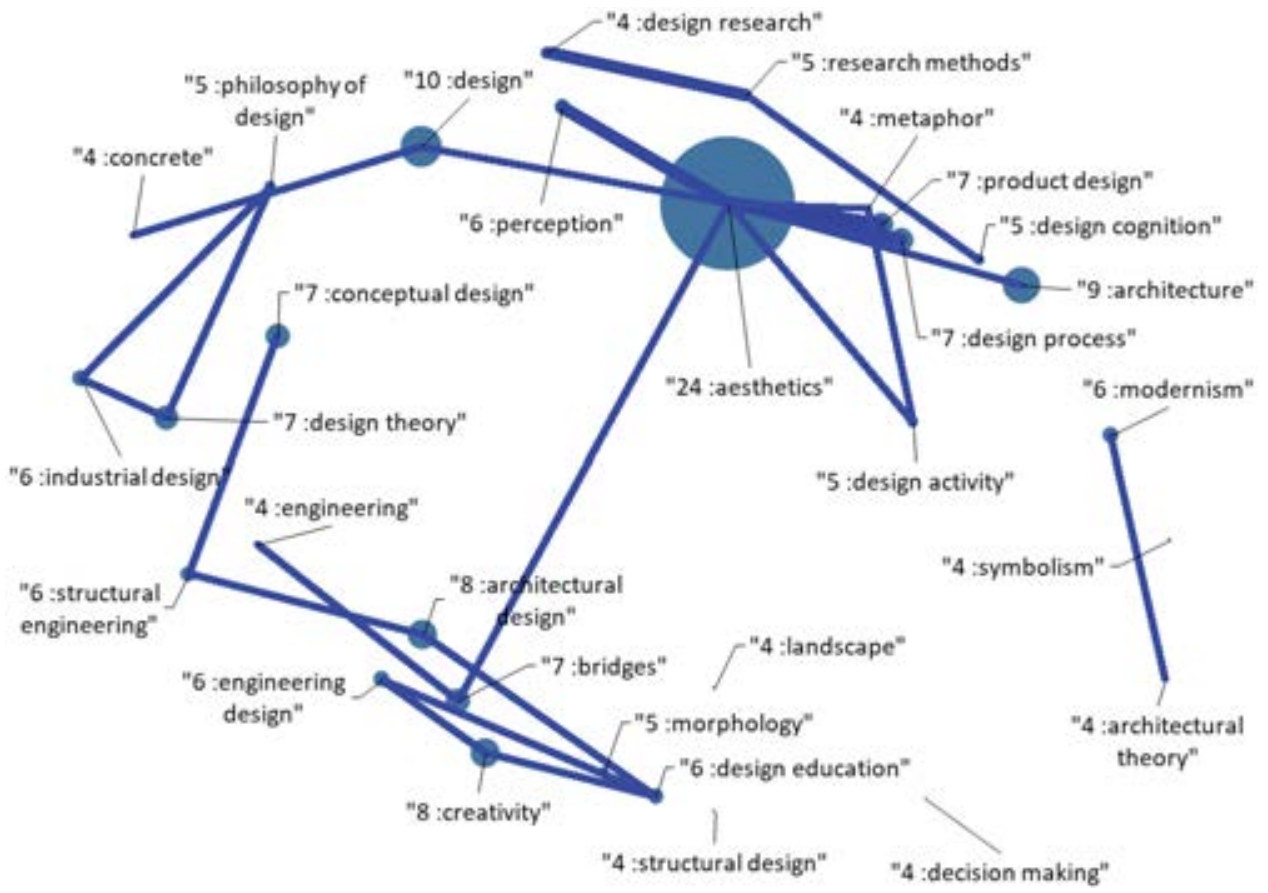

Figure 3: Scopus search for aesthetics with specific keywords

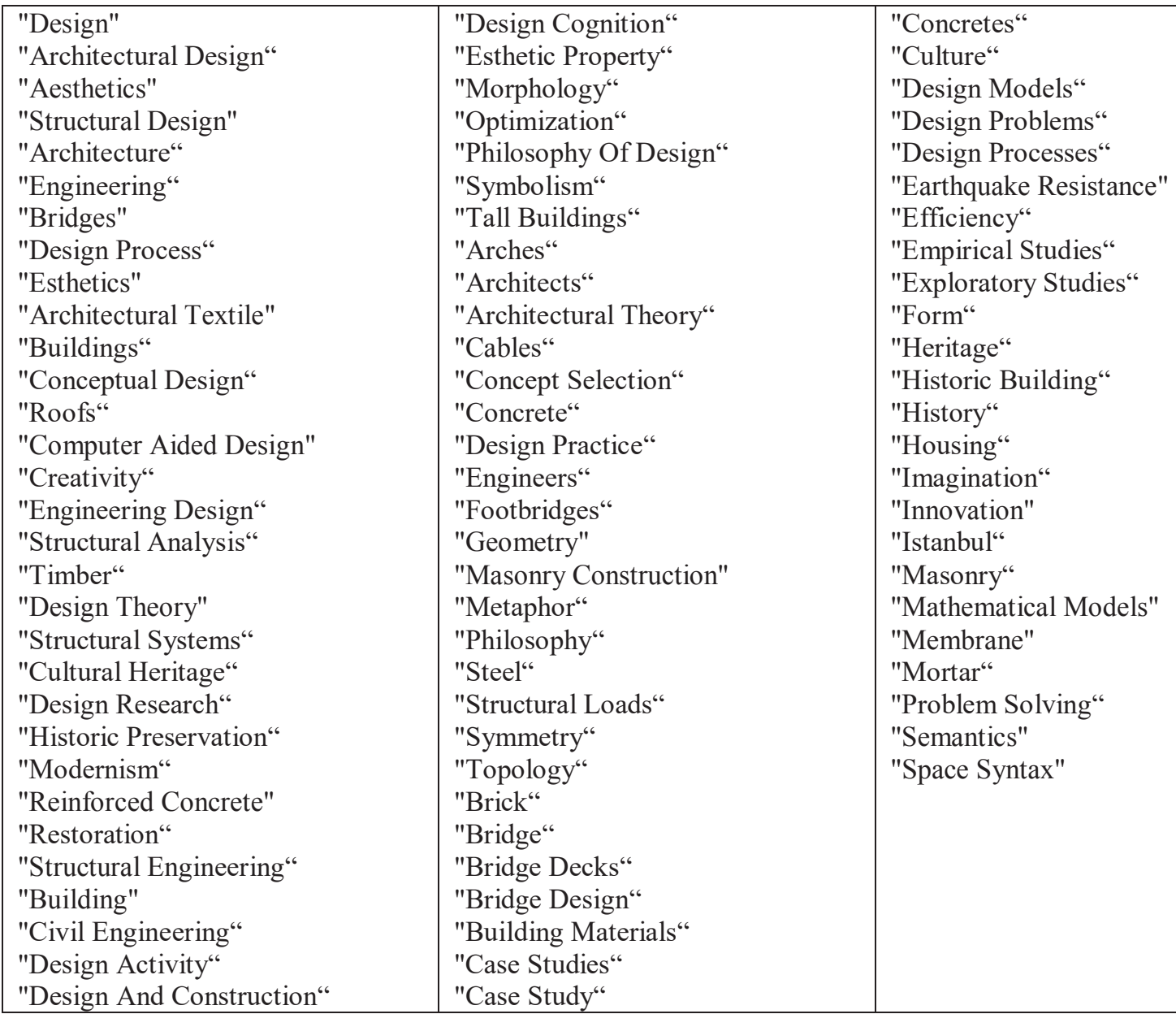

Table 1: Special keywords for the final database construction 


\section{STUDIED DATABASE}

Seventeen projects have been used, of which all had ten different, parametric variations, by changing the slider components in the software [2], [3], and have been created mainly by the third-year students of the school of architecture at Neapolis University Pafos, in their modules, Computational Design and Advanced Structural Systems. From these ten alterations, we get sixteen structural analysis results, regarding the maximum and minimum displacements, nodal rotations, internal axial forces and bending moments. All these results are included in Appendix II, while indicative results are demonstrated in Table 2. These sixteen output values from each variation of the projects, in combination with a questionnaire which was completed by architects, engineers and other people, not related to this profession, will be analyzed statistically in order to investigate the hypothesis that structural response is correlated with the aesthetic value of each project. The aesthetic value was considered as the mean value (for each project) of the participants to this research. The questionnaire was filed by 23 people and the mean value of the responses was used as the dependent variable, representing an unbiased indicator for aesthetic value.

\begin{tabular}{|c|c|c|c|c|c|c|c|c|c|c|c|c|c|c|}
\hline & $\mathrm{N}(\max )$ & $\mathrm{N}(\mathrm{avg})$ & $\mathrm{M}(\max )$ & $\mathrm{M}$ (avg) & $\mathrm{Tx}(\max )$ & Tx(avg) & $\operatorname{Ty}(\max )$ & $\mathrm{Tz}(\mathrm{avg})$ & $\operatorname{Rx}(\max )$ & $\operatorname{Rx}($ avg) & $\operatorname{Ry}(\max )$ & Ry(avg) & Rz(avg) & aesthetics \\
\hline 001 & $1.6 \mathrm{E}+00$ & $5.2 \mathrm{E}-01$ & $2.9 \mathrm{E}-01$ & $7.8 \mathrm{E}-02$ & $1.7 \mathrm{E}-04$ & 4.0E- 05 & $5.5 \mathrm{E}-05$ & $4.8 \mathrm{E}-05$ & $6.3 \mathrm{E}-05$ & $1.4 \mathrm{E}-05$ & $1.9 \mathrm{E}-04$ & $5.7 \mathrm{E}-05$ & 9.3E-06 & $4.2 \mathrm{E}+00$ \\
\hline 003 & $1.7 \mathrm{E}+00$ & $5.3 \mathrm{E}-01$ & $3.0 \mathrm{E}-01$ & 7.1E-02 & $1.7 \mathrm{E}-04$ & 3.4E- 05 & $6.9 \mathrm{E}-05$ & $4.2 \mathrm{E}-05$ & $7.5 \mathrm{E}-05$ & $1.5 \mathrm{E}-05$ & $1.9 \mathrm{E}-04$ & $4.9 \mathrm{E}-05$ & 1.1E- 05 & $3.9 \mathrm{E}+00$ \\
\hline 004 & $1.7 \mathrm{E}+00$ & $5.4 \mathrm{E}-01$ & $3.1 \mathrm{E}-01$ & $8.2 \mathrm{E}-02$ & $2.0 \mathrm{E}-04$ & 4.5E- 05 & $5.1 \mathrm{E}-05$ & $5.4 \mathrm{E}-05$ & $9.2 \mathrm{E}-05$ & $1.5 \mathrm{E}-05$ & 2.1E-04 & $6.1 \mathrm{E}-05$ & $8.8 \mathrm{E}-06$ & $3.8 \mathrm{E}+00$ \\
\hline 006 & $1.5 \mathrm{E}+00$ & $4.4 \mathrm{E}-01$ & 2.4E- 01 & $5.6 \mathrm{E}-02$ & $1.0 \mathrm{E}-04$ & 2.1E- 05 & $3.7 \mathrm{E}-05$ & $2.6 \mathrm{E}-05$ & $5.3 \mathrm{E}-05$ & $8.8 \mathrm{E}-06$ & $1.4 \mathrm{E}-04$ & 3.6E- 05 & $8.0 \mathrm{E}-06$ & $3.8 \mathrm{E}+00$ \\
\hline 007 & $1.4 \mathrm{E}+00$ & 4.2E- 01 & $1.9 \mathrm{E}-01$ & $5.1 \mathrm{E}-02$ & $7.0 \mathrm{E}-05$ & $1.5 \mathrm{E}-05$ & $3.1 \mathrm{E}-05$ & $1.9 \mathrm{E}-05$ & $3.4 \mathrm{E}-05$ & $7.6 \mathrm{E}-06$ & $8.6 \mathrm{E}-05$ & $2.8 \mathrm{E}-05$ & $6.5 \mathrm{E}-06$ & $3.8 \mathrm{E}+00$ \\
\hline 008 & $1.4 \mathrm{E}+00$ & 4.3E- 01 & $1.9 \mathrm{E}-01$ & $5.5 \mathrm{E}-02$ & $6.7 \mathrm{E}-05$ & $1.8 \mathrm{E}-05$ & $3.0 \mathrm{E}-05$ & $2.2 \mathrm{E}-05$ & $3.1 \mathrm{E}-05$ & $8.0 \mathrm{E}-06$ & $8.7 \mathrm{E}-05$ & 3.2E- 05 & $6.4 \mathrm{E}-06$ & $3.8 \mathrm{E}+00$ \\
\hline
\end{tabular}

Table 2: Structural analysis results for structure 001-010

The numerical procedure was started by creating ten versions of each project by using the software Rhino [4], and its plugin Grasshopper3d [3] and then save ten renders from a different viewing point of each alteration. For the static solution of these projects the plugin Karamba3d [2], [5] was used, in which we came up with the maximum and minimum internal forces and also the maximum and minimum displacements. Furthermore, a questioner on Google docs (Appendix I), was created with all the images, which are included in Appendix III, in order for people to vote. From this feedback, an excel file was created so as to be analyzed with regression analysis. Furthermore, the top five projects that were voted, are demonstrated in Figure 7. Finally, two examples of the code that was used in Grasshoper3d, and one example code from Karamba3d are depicted in Appendix III.

In Figure 7 - A, which is a curved hanging bridge, the concept is to rotate around from its vertical axis to pass the ships under the bridge. Figure $7-\mathrm{B}$, is a hanging bridge in a straight line similar to the previous one. In Figure $7-C$, we still demonstrate a hanging bridge of similar structural rationale, in the simplest form. In Figure 7 - D, we show a parametric shell with polygonal openings on the roof. Finally, in Figure 7 - E a large-scale enclosure is demonstrated. Accordingly, in, Figure10, the corresponding code in the Grasshopper3d [3] program and the congruent code is for the project of Figure 7-B. Then the code for the project of Figure 7$\mathrm{A}$ is demonstrated in Figure 11 with an optimization tool to the right in order to find a place where the bridge has the minimum bending moments. Finally, for the same project, we see the 
Karamba3d [2] code and the various values we output for moments and displacements (see Figure 12 in Appendix II).
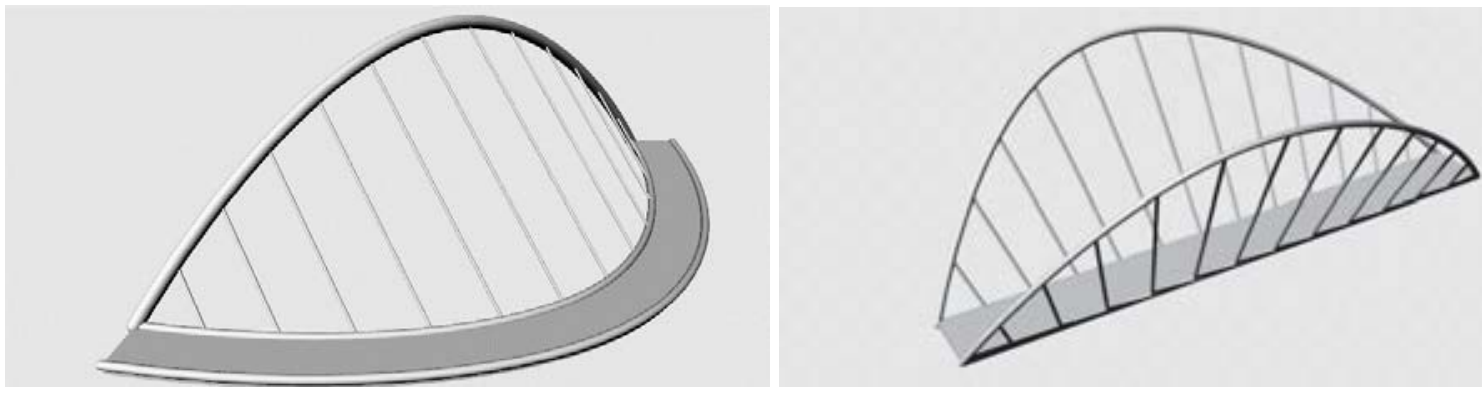

A-B: Parametric projects 215, 226
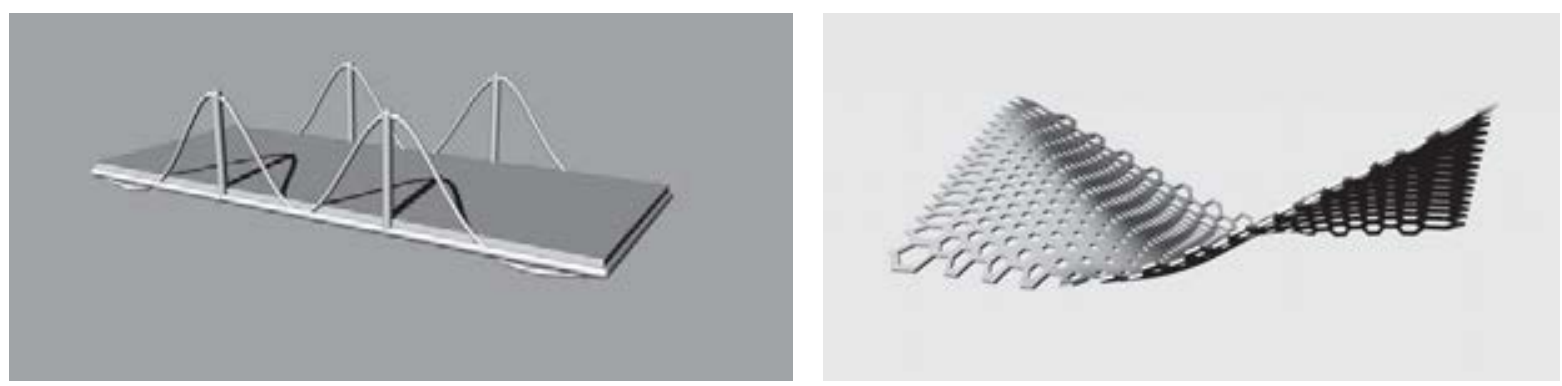

C-D: Parametric projects 081, 236

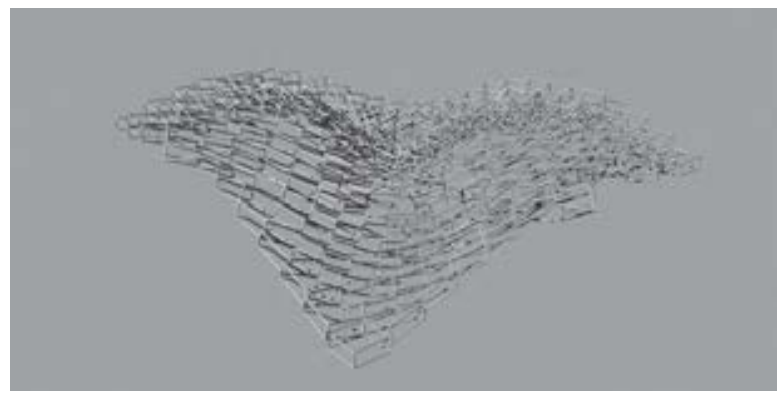

E: Parametric project 107

Figure 4: Highest rated projects

\section{HEADINGS}

In order to perform the regression analysis, the results of each project were normalized to have zero mean and unit standard deviation, so as to utilize the same range for the Karamba3d results for its project and the statistical analysis to be more representative. The projects with irrational values of internal forces were excluded from the database via anomaly detection software [26], as they probably had errors in the connectivity of the model. We used three Machine Learning simulations, in order to construct prediction models, and in particular, Linear Regression [27], Random Forests [28], [29], and Gradient Boosting [30], [31], as developed in Julia [32] programming language. In Table 3, the accuracy metrics indicate a strong link among the structural analysis results, with the aesthetic value, as computed by the questionnaires. Afterwards, sensitivity analysis [33], [34] was conducted in order to investigate the influence of each independent variable to the dependent, by keeping all other variables constant at their Median value. In Figure 8, the corresponding results for Aesthetic value vs Bending Moments over Axial Forces are depicted, exhibiting a decreasing pattern. This is in accordance with the rationale of Antonio Gaudi [7] and the minimum bending moments of arches and domes. 


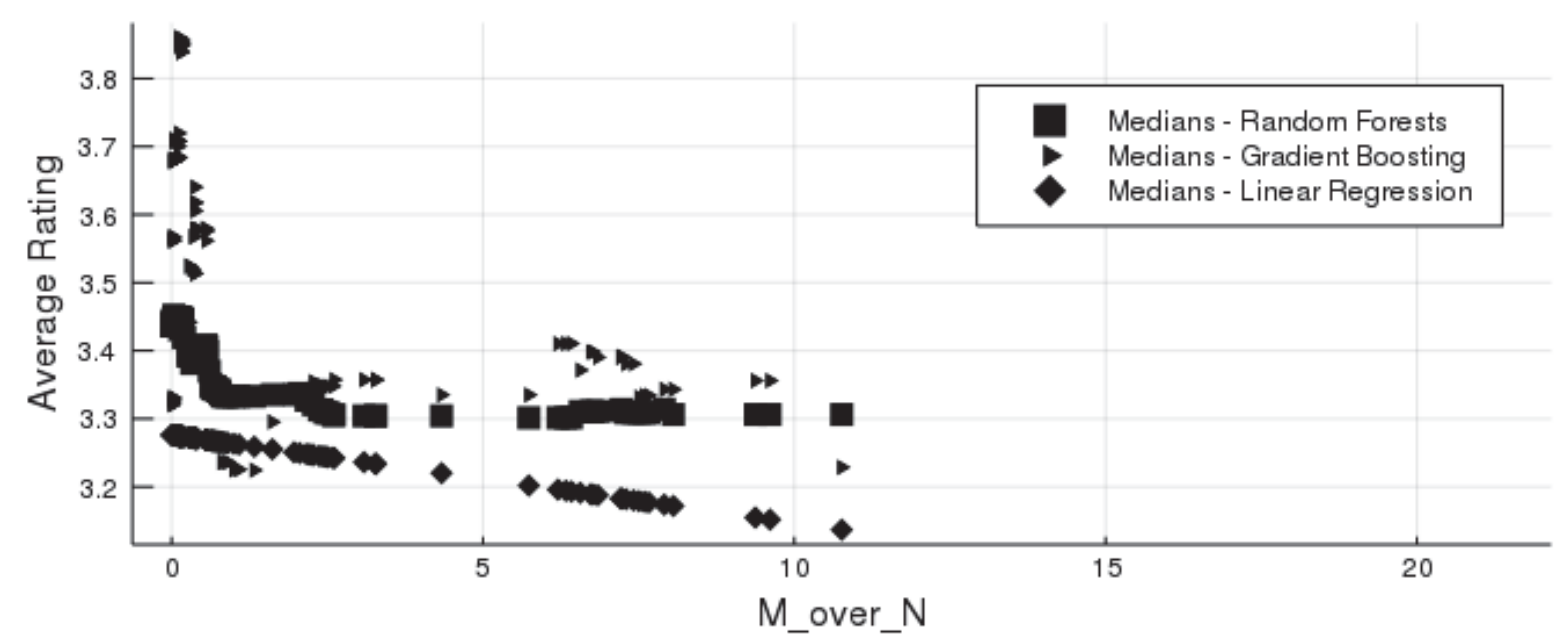

Figure 5: Sensitivity analysis

\begin{tabular}{l|cccccc} 
Methods & Pears. Corr. & MAE & RMSE & MAPE & MAXPE & Alpha \\
\hline \hline Random Forests & 0.8156 & 0.1460 & 0.1980 & 0.0466 & 0.2065 & 0.5704 \\
Gradient Boosting & 0.9732 & 0.0183 & 0.0771 & 0.0055 & 0.1761 & 0.9469 \\
Linear Regression & 0.3769 & 0.2449 & 0.3155 & 0.0800 & 0.3533 & 0.1154
\end{tabular}

Table 3: Accuracy Metrics of Machine Learning Models

\section{CONCLUSIONS}

This research was an attempt to contribute to the question of many architects and civil engineers on whether the structural response of a structure is useful to the stability of the building, or it has another utilization on the architectural synthesis as well. The literature regarding parametric design and form-finding, although indirectly refer to the aesthetics of the structure, lack any identification of a numerical link between the structural response and aesthetics of the structure. This was farther investigated and confirmed with bibliometric analysis of the literature regarding aesthetics and structural response, where the clusters of the aesthetic related keywords were separated from the engineering related keywords. An adequate amount of projects (170) were developed and studied in order to construct a database for such an investigation. The regression analysis confirmed numerically that there exists a link between structural response and aesthetics.

\section{ACKNOWLEDGEMENTS}

Special thanks to the students which participated in this study, by offering their studio projects:

Mais-Wakid Abbas, Theodoros Antoniou, Christina Georgiou, Rafaella Georgiou, Maria Giannaka, Panagiotis Kontopyrakis, Iuliia Logacheva, Maria-Pavlina Pavloudaki, ElinaStergia Pieri, Demetris Socratous, Elenos Tsigkis, Maria-Evangelia Tzouveleki.

\section{REFERENCES}

[1] J. Monedero, Parametric design: A review and some experiences, Autom. Constr., 2000.

[2] C. Preisinger and others, Karamba3D, Version, vol. 1, no. 2, p. 25, 2015. 
[3] Grasshopper3d. 2019.

[4] Rhino3d. Robert McNeel \& Associates, 2019.

[5] C. Preisinger, Linking structure and parametric geometry, Archit. Des., 2013.

[6] C. Preisinger, Karamba3D User Manual (Version 1.3.2). 2019.

[7] A. Pugnale and M. Sassone, Morphogenesis and structural optimization of shell structures with the aid of a genetic algorithm, in Journal of the International Association for Shell and Spatial Structures, 2007.

[8] S. Huerta, Structural design in the work of gaudí, Archit. Sci. Rev., 2006.

[9] M. Dimcic, Structural Optimization of Grid Shells Based on Genetic Algorithms. 2011.

[10] S. Schoina, Performance-based form-finding and material distribution of free form roof structures: Implementation in the Post Rotterdam Case Study, 2016.

[11] J. S. GERO, Architectural Optimization-A Review, Eng. Optim., vol. 1, no. 3, pp. 189199, 1975.

[12] A. J. Isaacs, Self-Organisational Architecture: Design Through Form-Finding Methods, J. Chem. Inf. Model., 2013.

[13] M. Turrin, P. Von Buelow, and R. Stouffs, Design explorations of performance driven geometry in architectural design using parametric modeling and genetic algorithms, Adv. Eng. Informatics, vol. 25, no. 4, pp. 656-675, 2011.

[14] P. Basso, A. E. Del Grosso, A. Pugnale, and M. Sassone, Computational morphogenesis in architecture: Cost optimization of free-form grid shells, in Journal of the International Association for Shell and Spatial Structures, 2009.

[15] F. Otto, B. Rasch, D. W. Bayern, K. V. Stuck, and A. anlässlich der Preisverleihung des Deutschen Werkbundes Bayern an Frei Otto und Bodo Rasch, Frei Otto, Bodo Rasch: Finding form: towards on architecture of the minimal; the Werkbund shows Frei Otto, Frei Otto shows Bodo Rasch; exhibition in the Villa Stuck, Munich, on the occasion of the award of the 1992 Deutscher Werkbund Bayern Prize to Frei . Ed. Menges, 2006.

[16] R. A. P. E. Danhaive, Integrating interactive evolutionary exploration and parametric structural design, Massachusetts Institute of Technology, 2015.

[17] N. Oxman, Get Real towards Performance-Driven Computational Geometry, Int. J. Archit. Comput., 2007.

[18] A. Carlson, Aesthetics and the environment: The appreciation of nature, art and architecture. Routledge, 2005.

[19] S. Adriaenssens, P. Block, D. Veenendaal, and C. Williams, Shell structures for architecture: Form finding and optimization. 2014.

[20] N. D. Lagaros, M. Papadrakakis, and N. P. Bakas, Automatic minimization of the rigidity eccentricity of 3D reinforced concrete buildings, J. Earthq. Eng., vol. 10, no. 4, pp. 533-564, Jul. 2006.

[21] N. D. Lagaros, N. Bakas, and M. Papadrakakis, Optimum Design Approaches for Improving the Seismic Performance of 3D RC Buildings, J. Earthq. Eng., vol. 13, no. 3, pp. 345-363, Mar. 2009.

[22] S. Heyman, Google Books: a Complex and Controversial Experiment, New York Times, 2015.

[23] V. Plevris, N. Bakas, G. Markeset, and J. Bellos, Literature review of masonry structures under earthquake excitation utilizing machine learning algorithms, in Proceedings of the 6th International Conference on Computational Methods in Structural Dynamics and Earthquake Engineering (COMPDYN 2015), 2017, pp. 26852694.

[24] T. Dimopoulos and N. Bakas, An artificial intelligence algorithm analyzing 30 years of 
research in mass appraisals, Rel. Int. J. Real Estate L. Plan., vol. 2, no. 0, pp. 10-27, 2019.

[25] Scopus. [Online]. Available: https://scopus.com/home.uri.

[26] N. P. Bakas, NOESYS-AI Regression: A generic framework for predictive modeling and sensitivity analysis. 2018.

[27] T. Dimopoulos, H. Tyralis, N. P. Bakas, and D. Hadjimitsis, Accuracy measurement of Random Forests and Linear Regression for mass appraisal models that estimate the prices of residential apartments in Nicosia, Cyprus, $A d v$. Geosci., vol. 45, pp. 377-382, Nov. 2018.

[28] L. Breiman, Random Forrests, Mach. Learn., 2001.

[29] Luis Pedro Coelho, MILK: Machine Learning Toolkit - DecisionTree.j1. .

[30] B. XU and T. CHEN, XGBoost.j1. 2014.

[31] T. Chen and C. Guestrin, XGBoost: A scalable tree boosting system, in Proceedings of the ACM SIGKDD International Conference on Knowledge Discovery and Data Mining, 2016.

[32] J. Bezanson, A. Edelman, S. Karpinski, and V. B. Shah, Julia: A fresh approach to numerical computing, SIAM Rev., vol. 59, no. 1, pp. 65-98, 2017.

[33] J. D. Olden and D. A. Jackson, Illuminating the 'black box': A randomization approach for understanding variable contributions in artificial neural networks, Ecol. Modell., 2002.

[34] M. Gevrey, I. Dimopoulos, and S. Lek, Review and comparison of methods to study the contribution of variables in artificial neural network models, in Ecological Modelling, 2003. 


\section{Appendix I: Figures, of the studied projects}

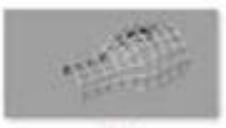

001

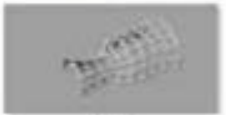

006

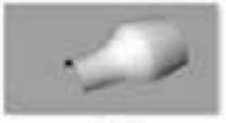

011

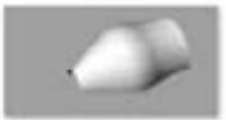

016

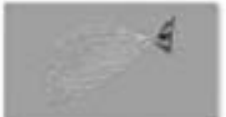

041

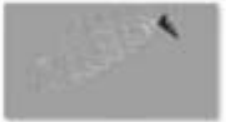

046

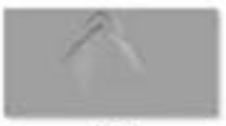

051

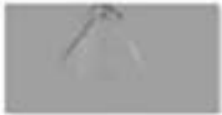

056

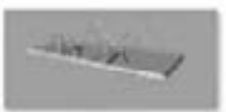

081

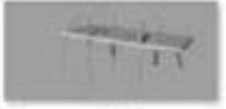

086

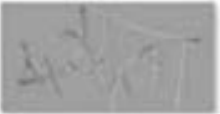

091

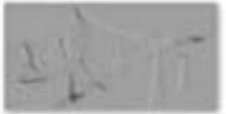

096

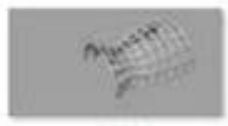

002

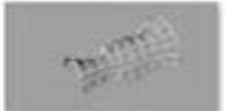

007

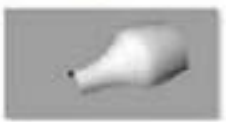

012

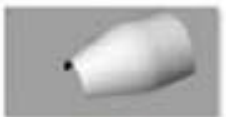

017

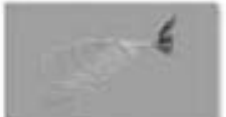

042

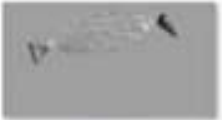

047

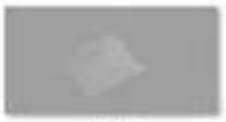

052

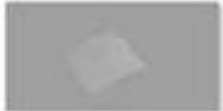

057

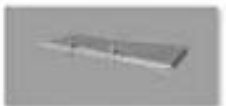

082

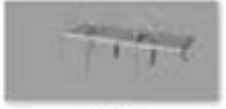

087

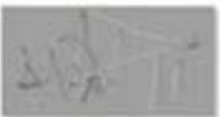

092

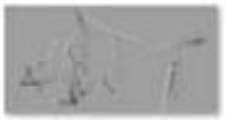

097

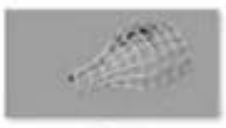

003

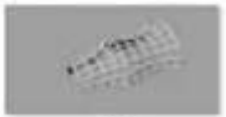

008

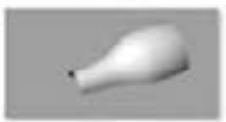

013

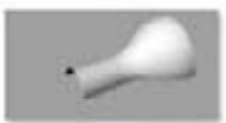

018

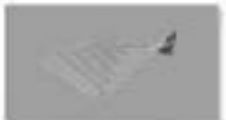

0.43

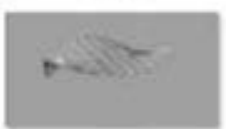

048

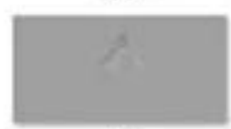

053

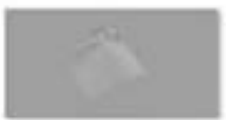

058

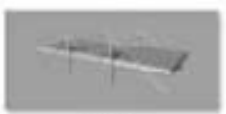

083

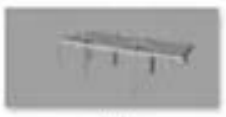

088

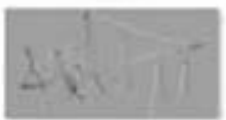

093

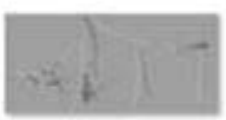

098

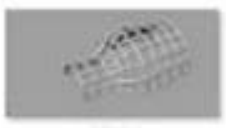

004

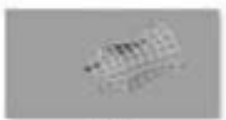

009

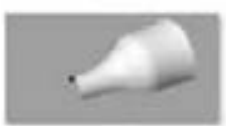

014

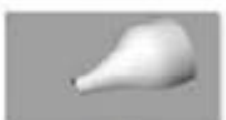

019

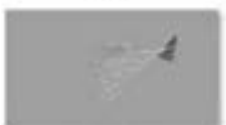

0.44

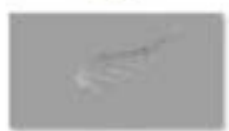

049

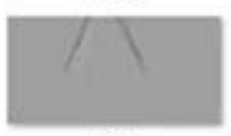

054

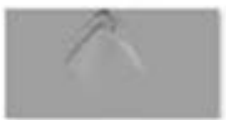

059

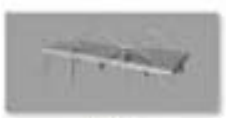

084

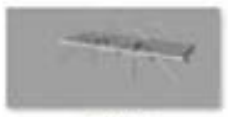

089

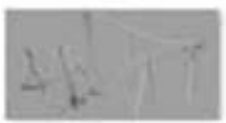

094

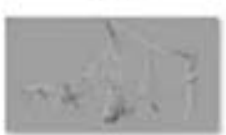

099

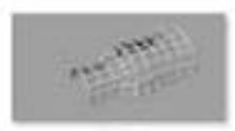

005

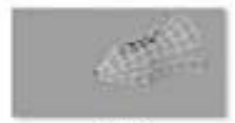

010

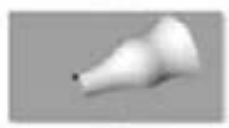

015

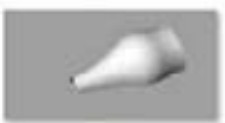

020

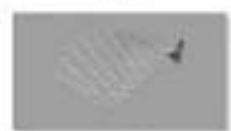

045

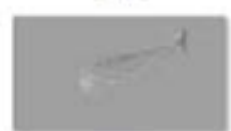

OSO

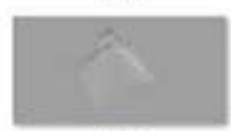

055

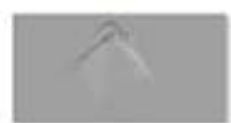

060

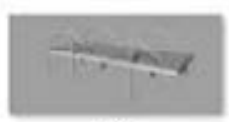

085

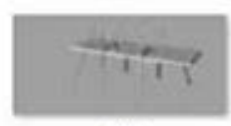

090

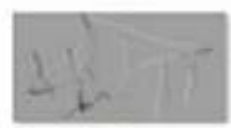

095

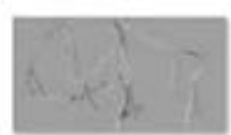

100 


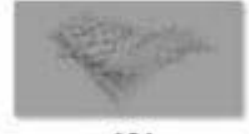

101

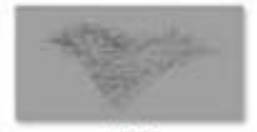

106

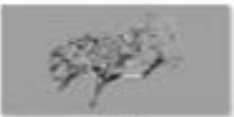

111

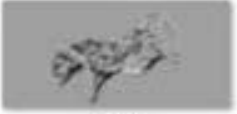

116

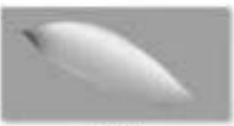

131

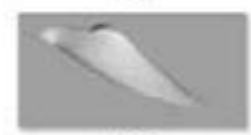

136

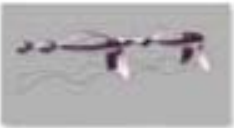

151

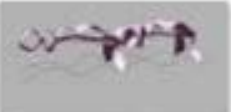

156

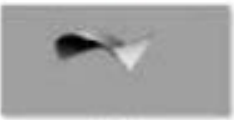

161

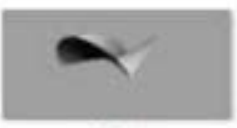

166

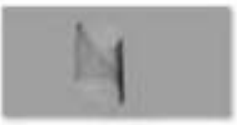

171

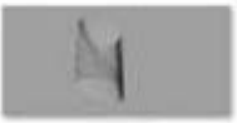

176

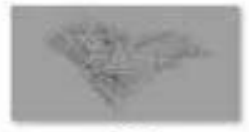

102

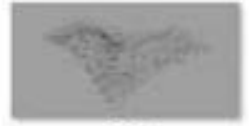

107

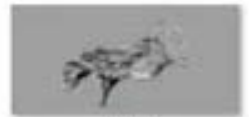

112

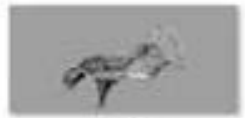

117

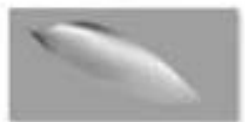

132

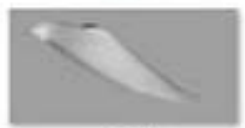

137

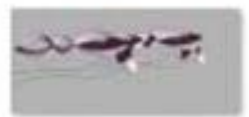

152

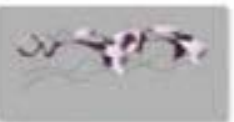

157

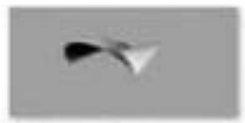

162

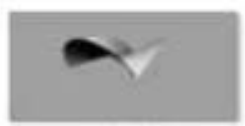

167

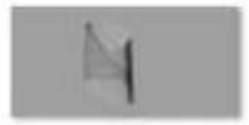

172

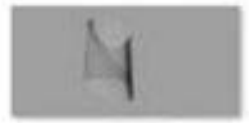

177

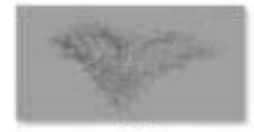

103

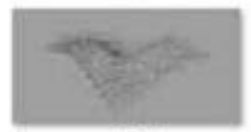

108

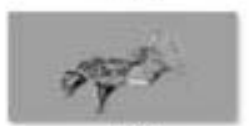

113

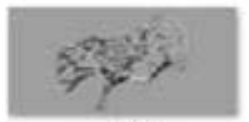

118

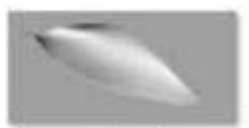

133

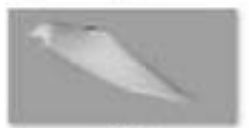

138

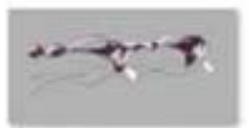

153

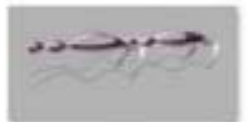

158

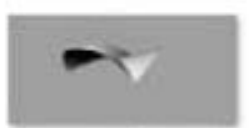

163

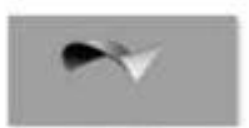

168

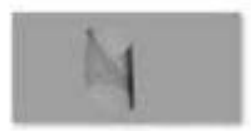

173

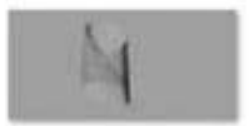

178

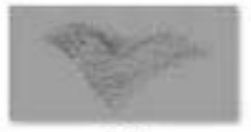

104

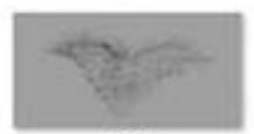

109

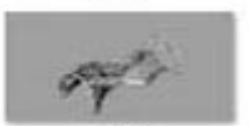

114

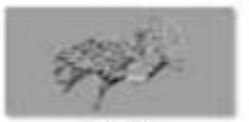

119

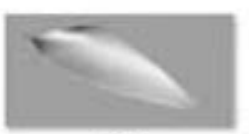

134

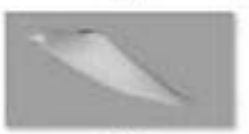

139

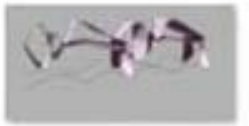

154

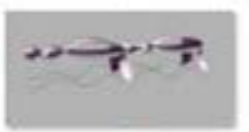

159

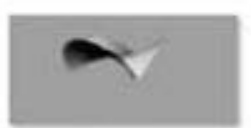

164

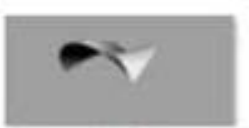

169

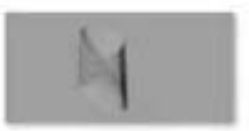

174

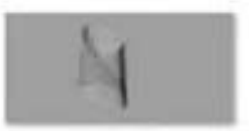

179

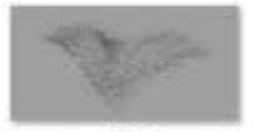

105

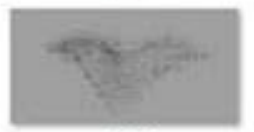

110

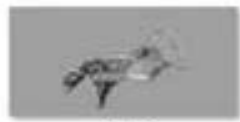

115

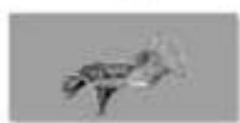

120

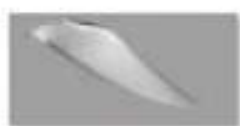

135

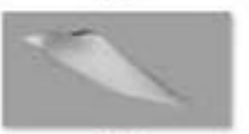

140

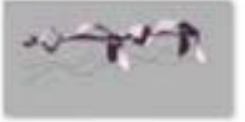

155

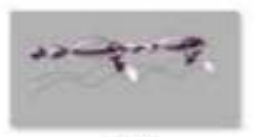

160

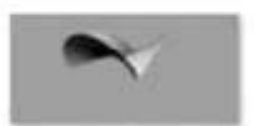

165

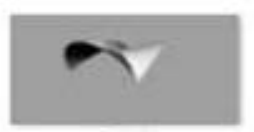

170

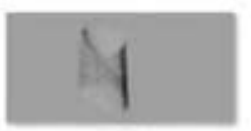

175

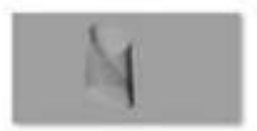

180 


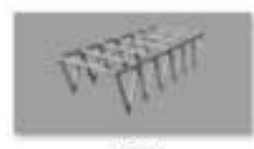

191

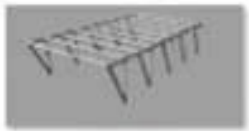

196

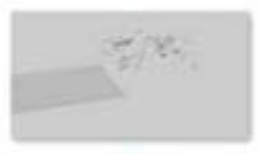

201

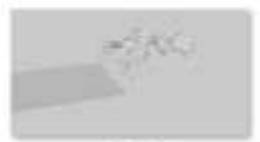

206

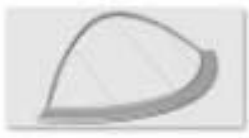

211

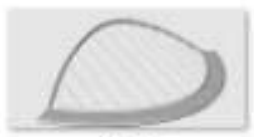

216

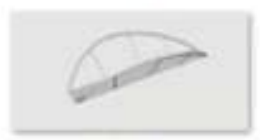

221

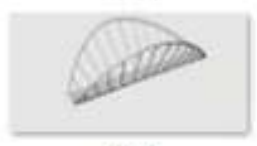

226

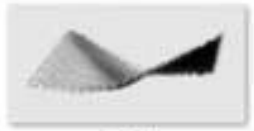

231

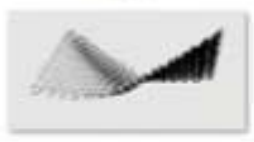

236

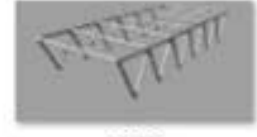

192

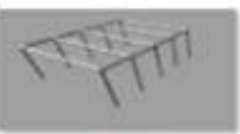

197

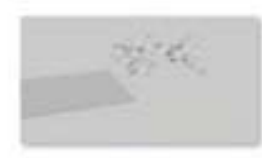

202

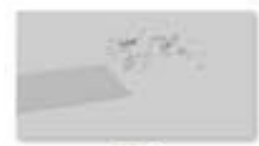

207

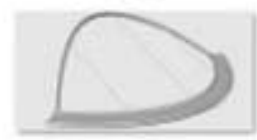

212

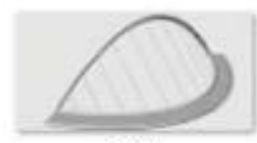

217
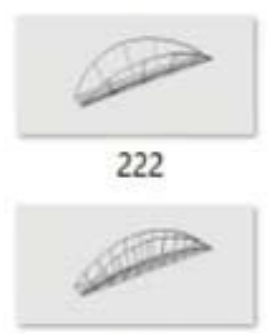

227

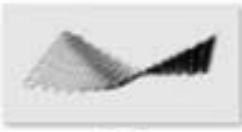

232

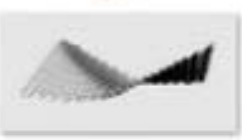

237

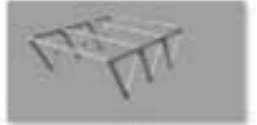

193

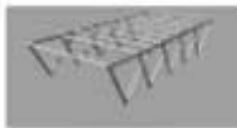

198

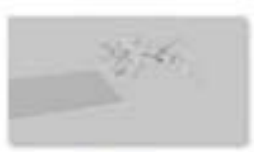

203

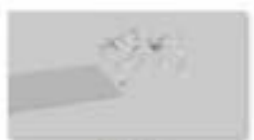

208

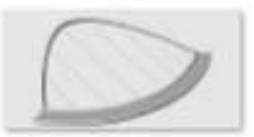

213

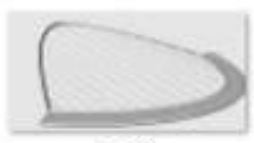

218

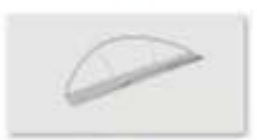

223

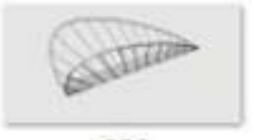

228

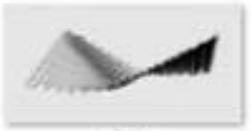

233

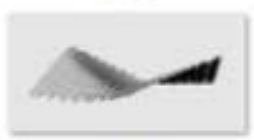

238

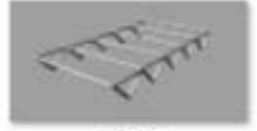

194

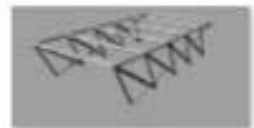

199

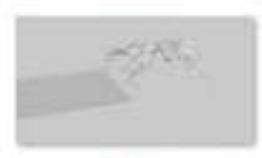

204

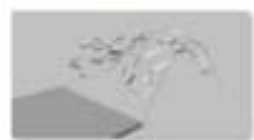

209

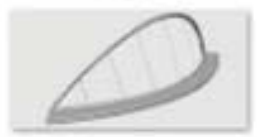

214

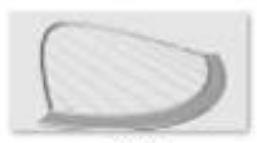

219

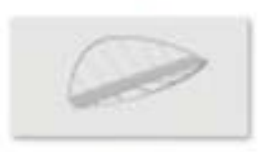

224

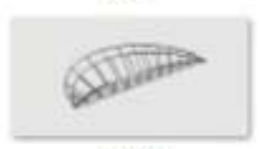

229

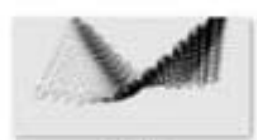

234

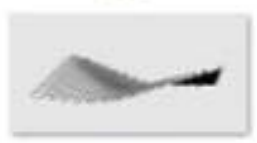

239

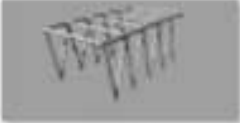

195

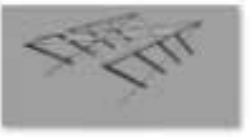

200

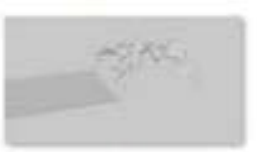

205

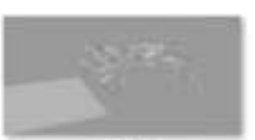

210

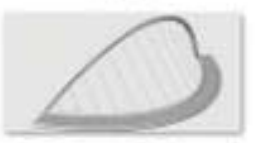

215

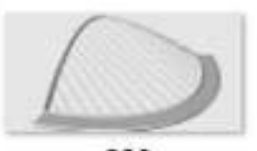

220
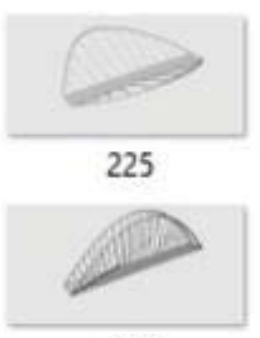

230

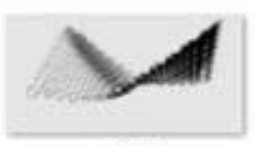

235

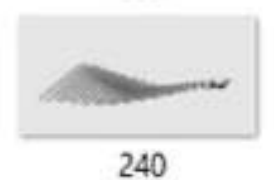




\section{Appendix II: Example Codes}

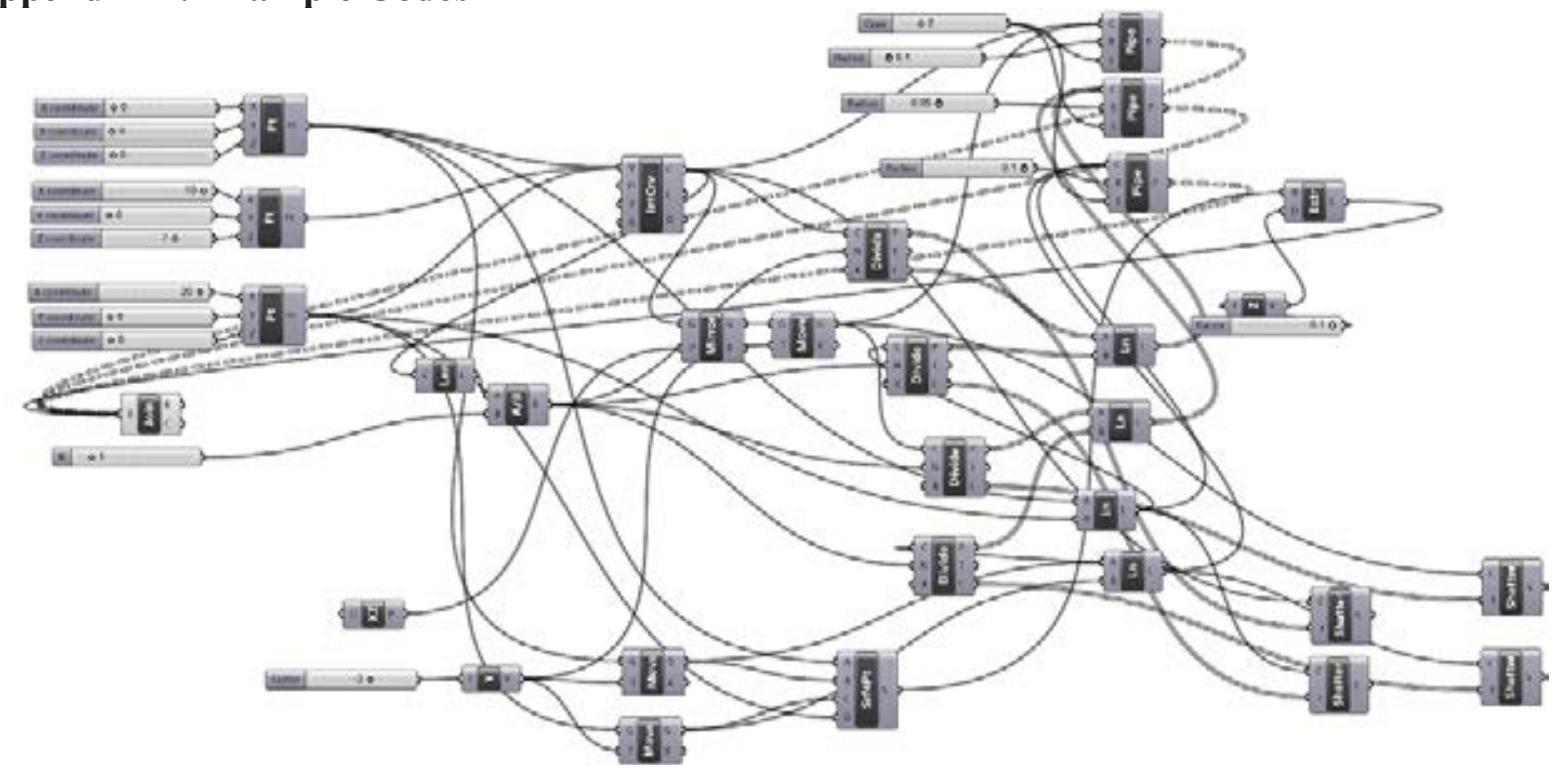

Figure 6: Parametric code 226

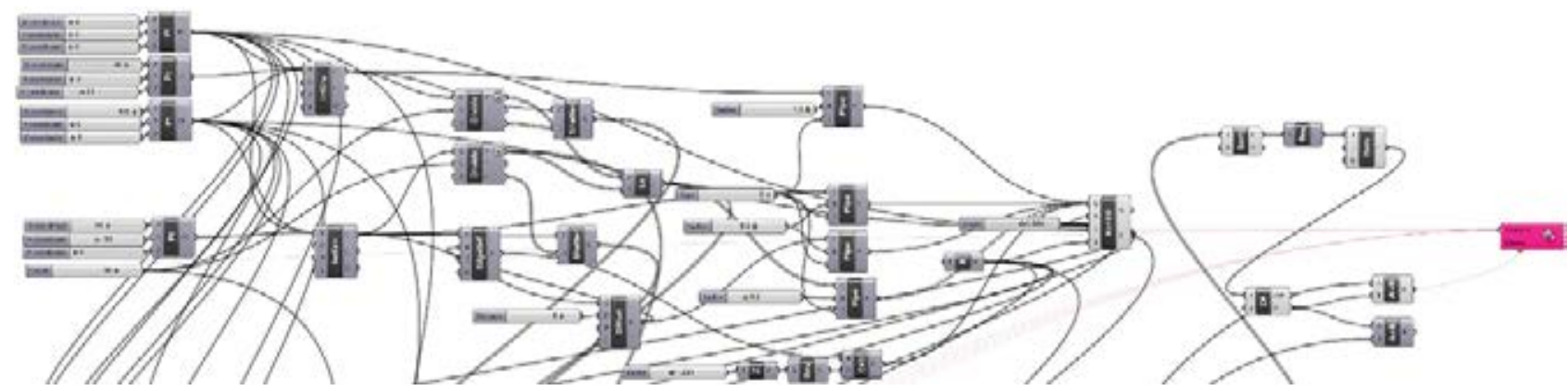

Figure 7: Parametric code 215

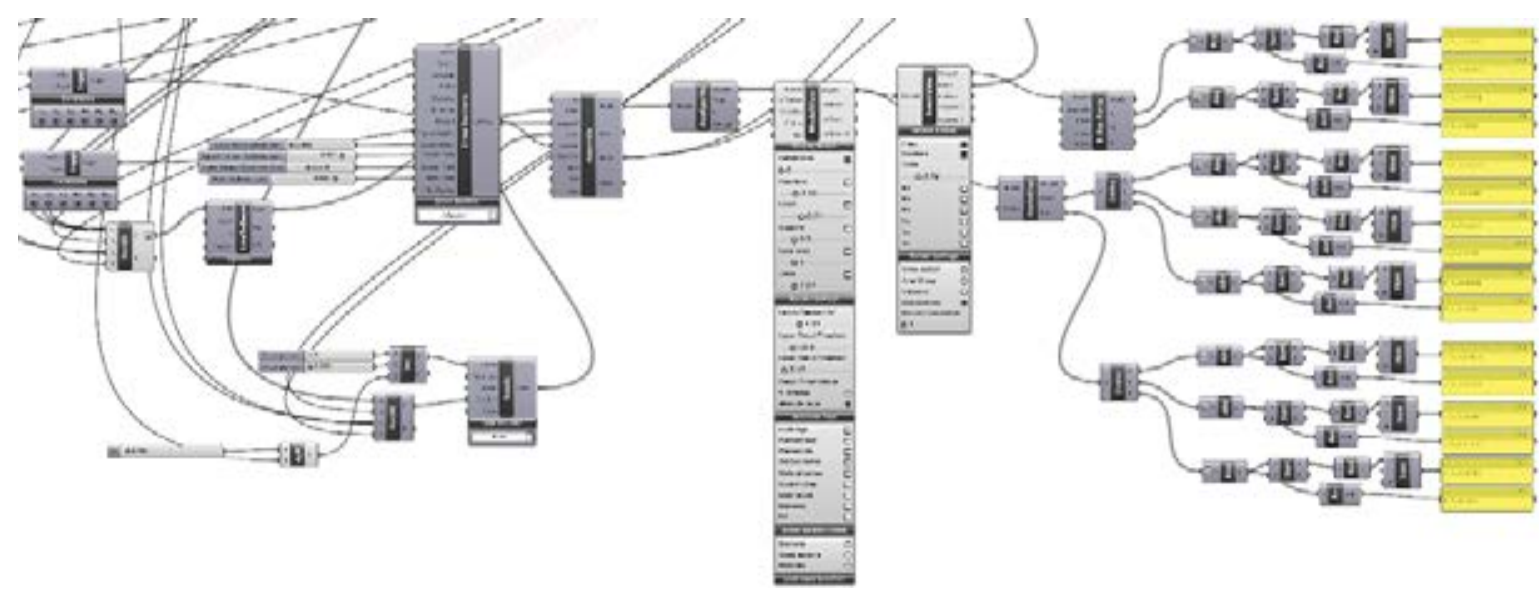

Figure 12: Karamba3d code 215 


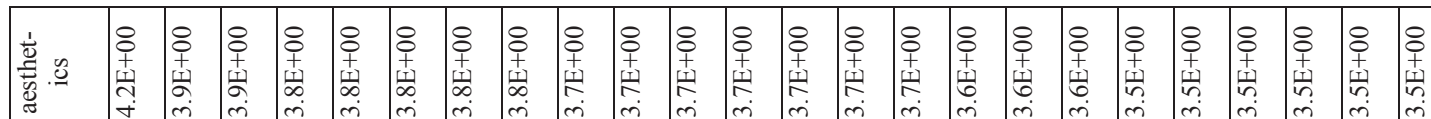

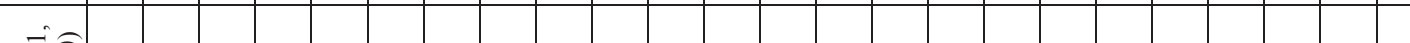

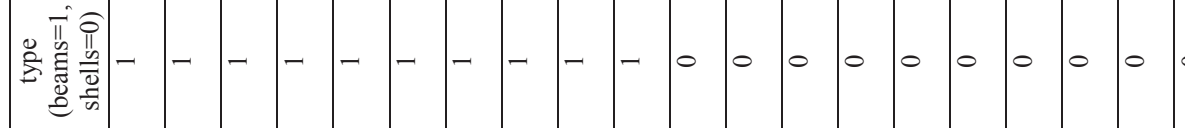

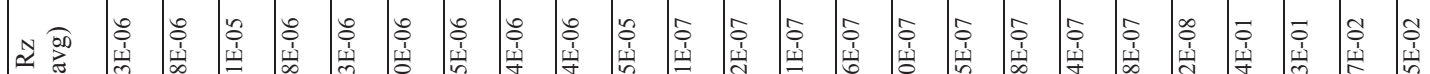

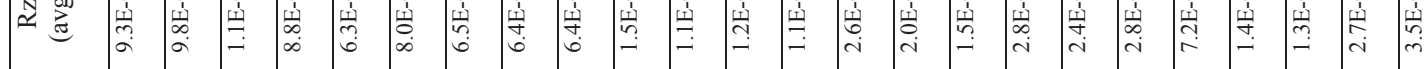

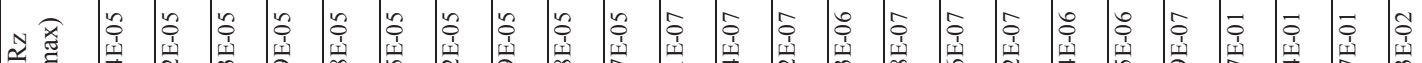

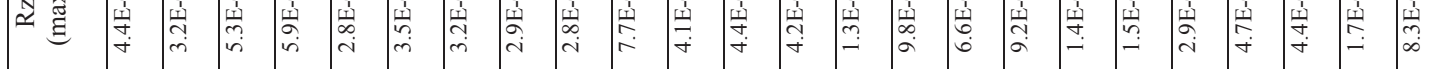

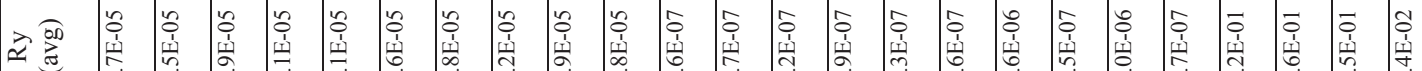

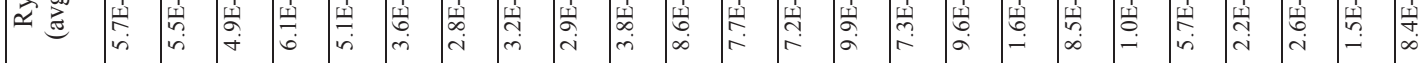

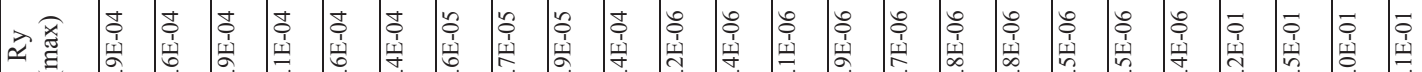

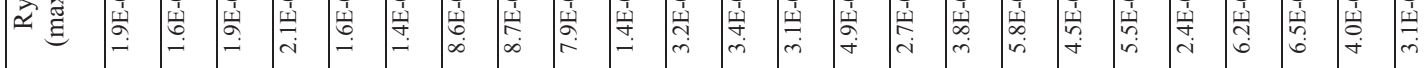

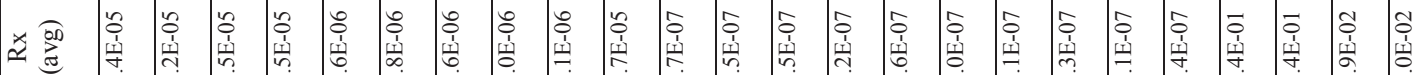
- I I

飞死

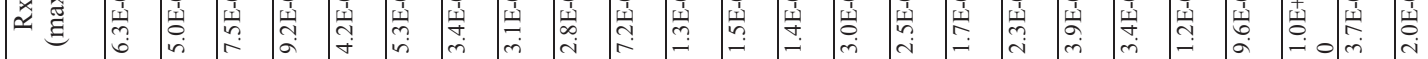

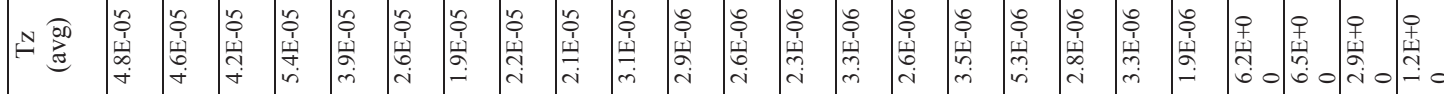

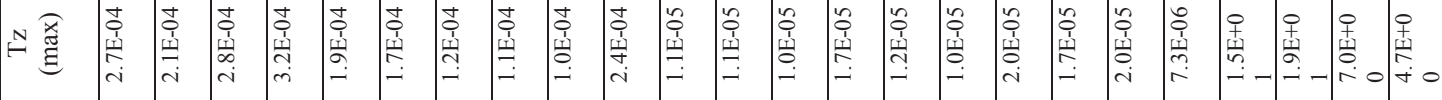

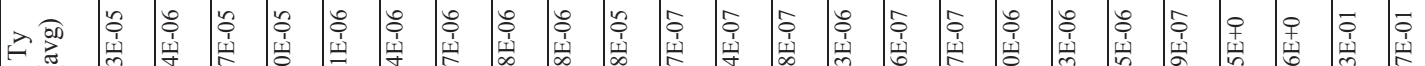

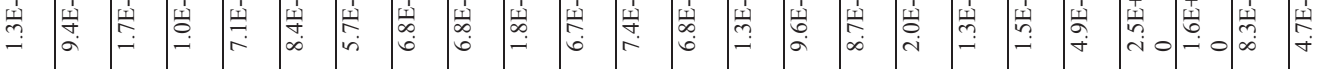

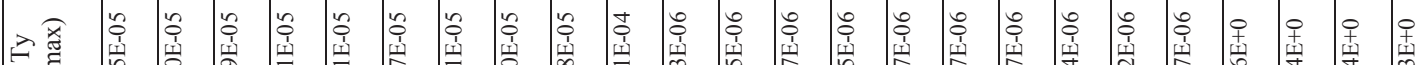

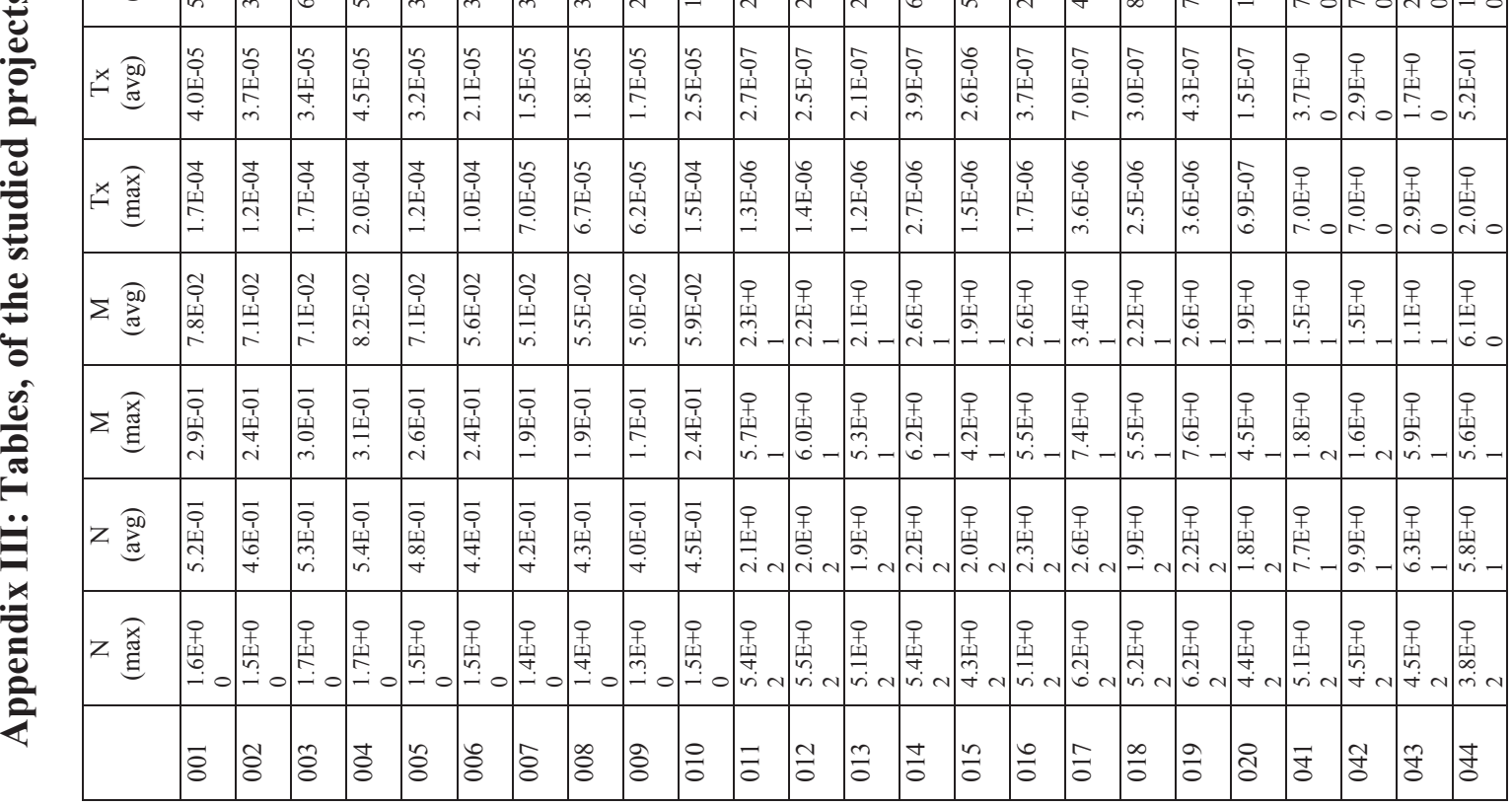




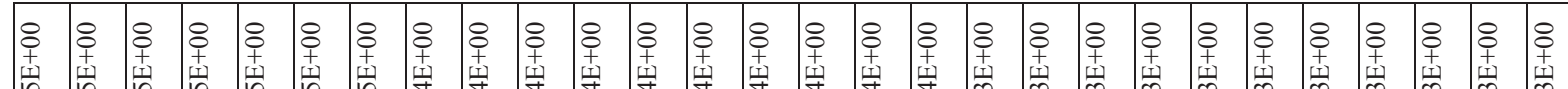

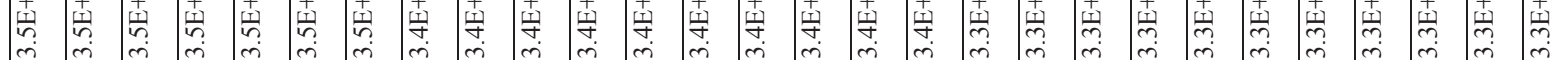

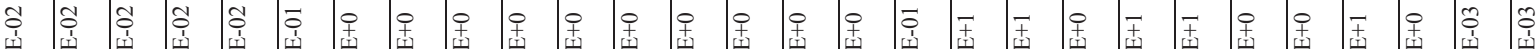

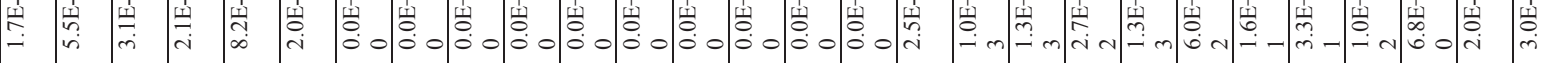

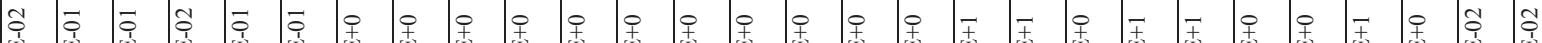

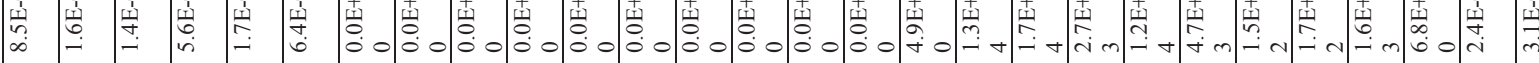

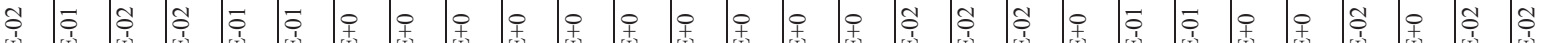

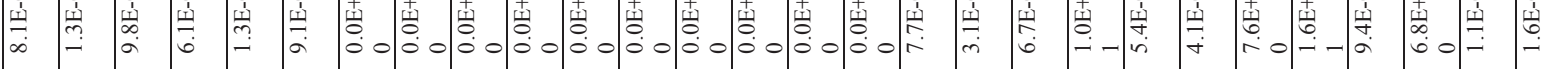

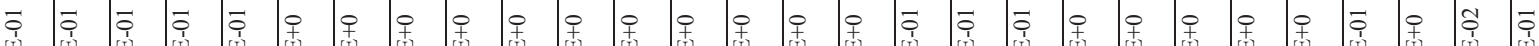

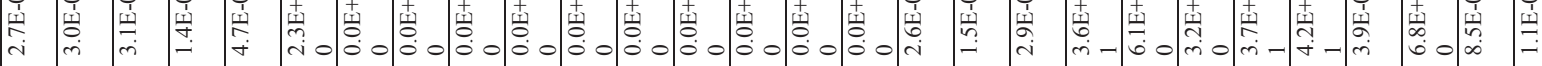

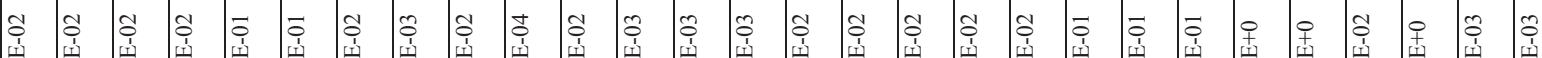

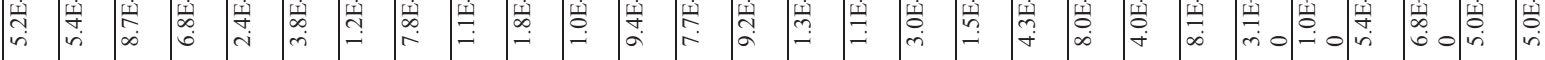

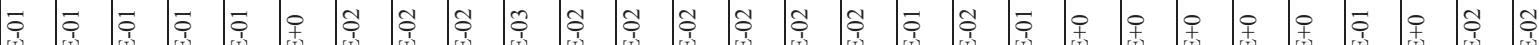

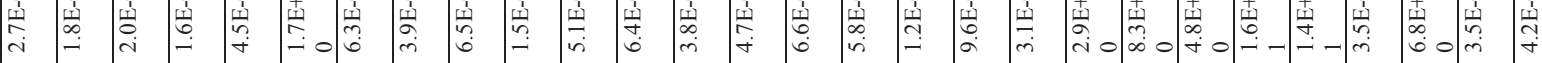

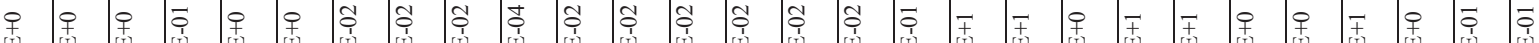

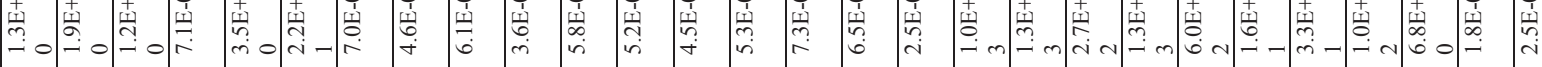
o o l o l

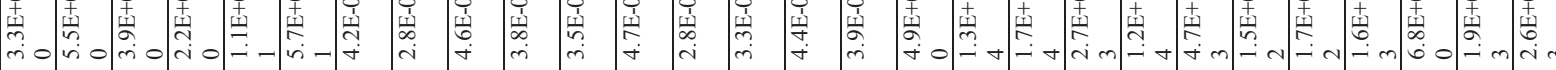
ప

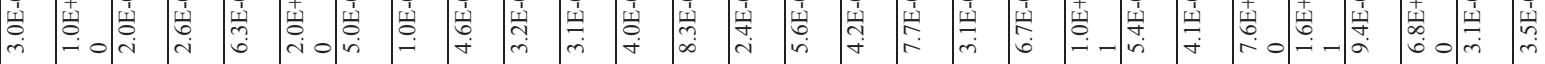

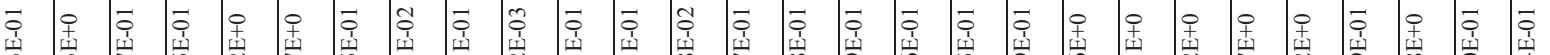

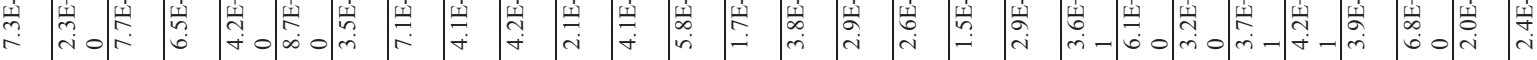

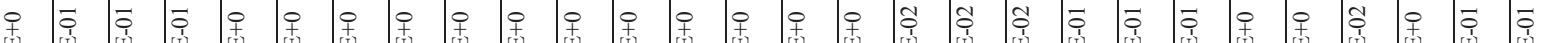

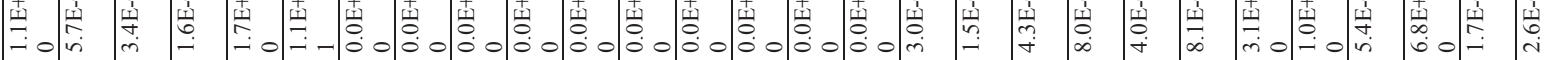

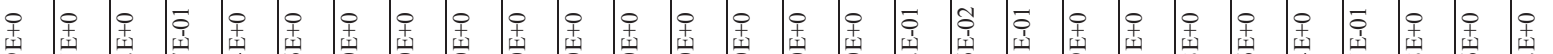

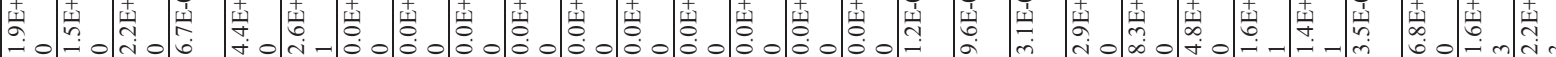

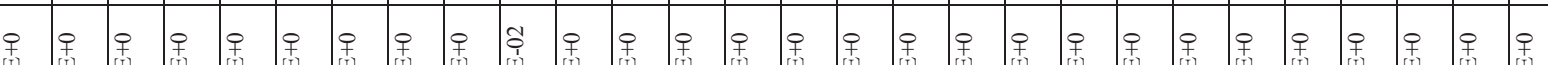

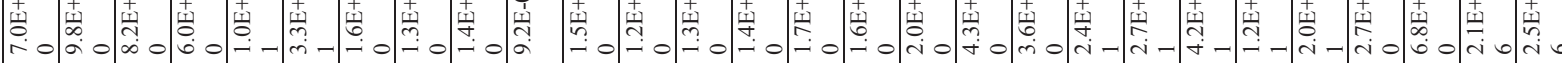

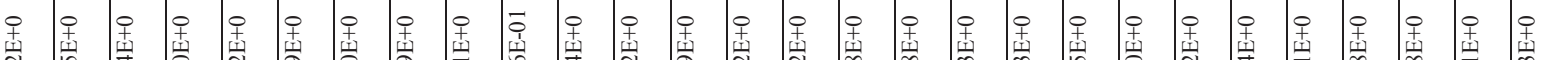

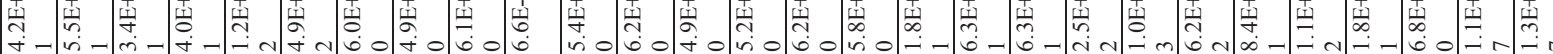

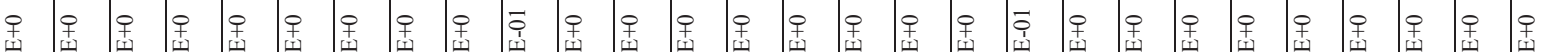
重_-

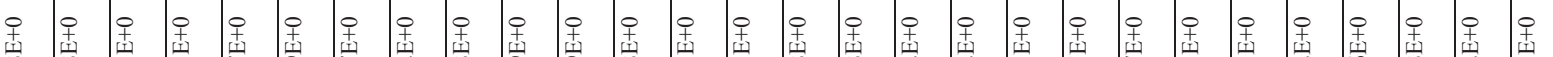

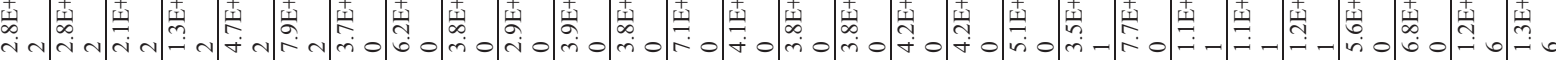

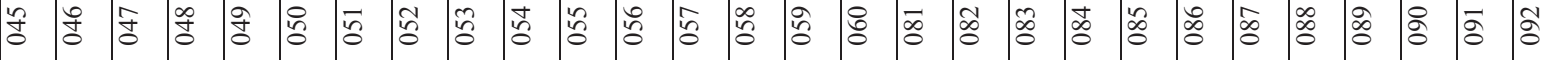




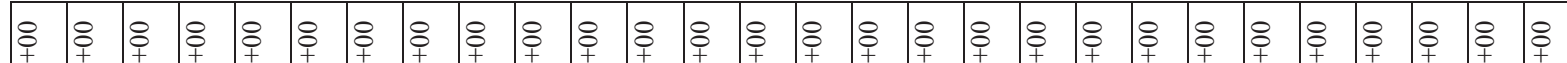

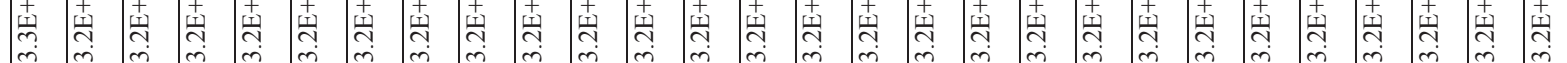

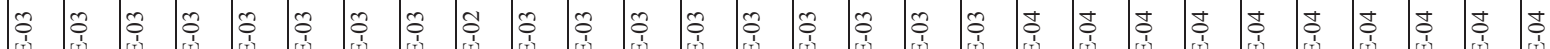

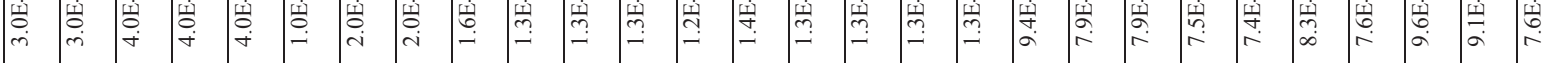

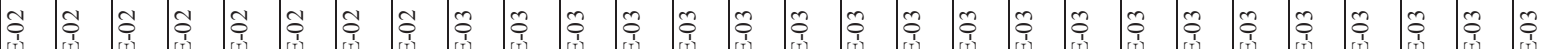

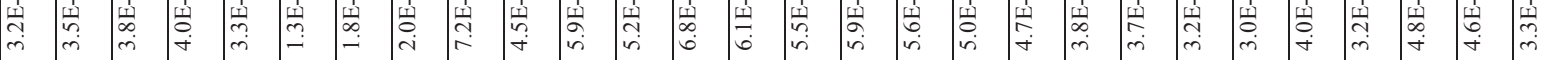

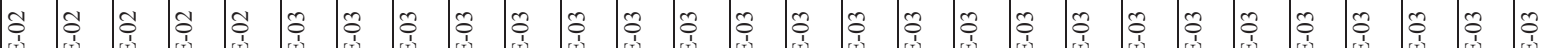

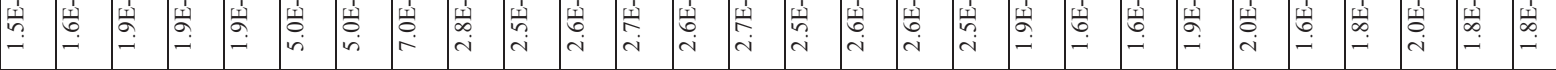

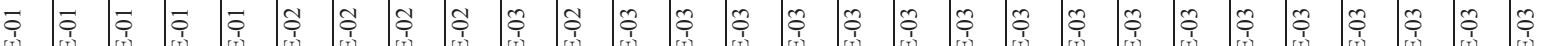

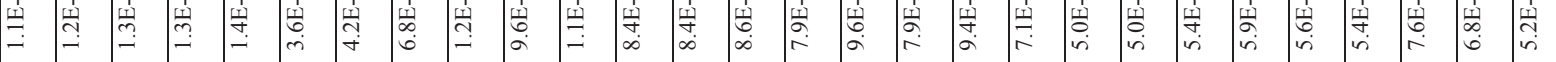

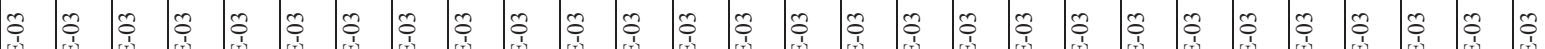

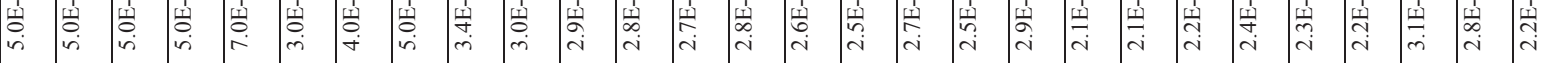

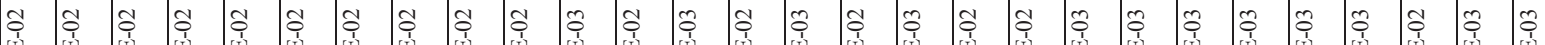

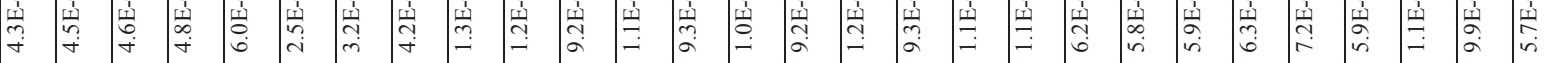

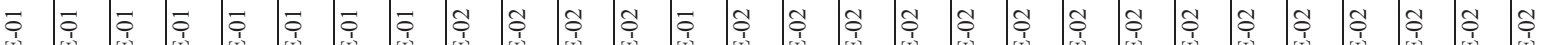

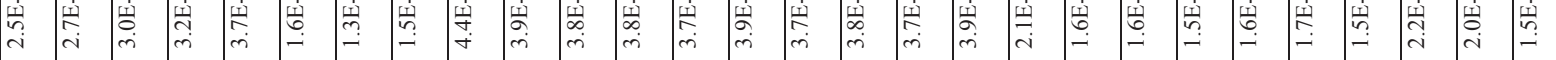

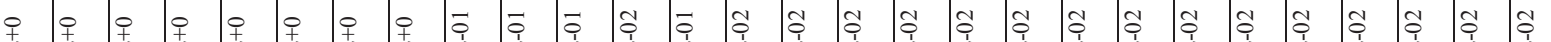

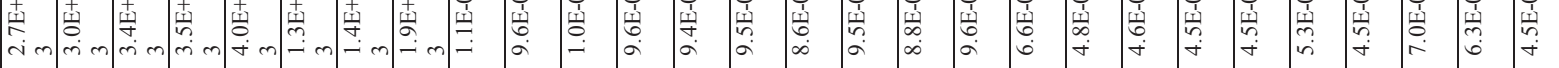

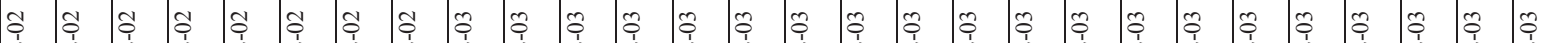

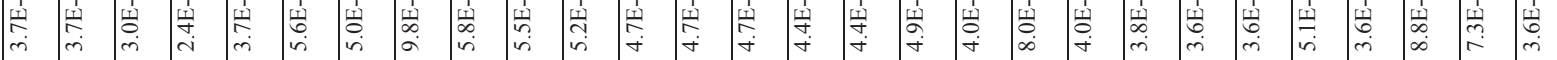

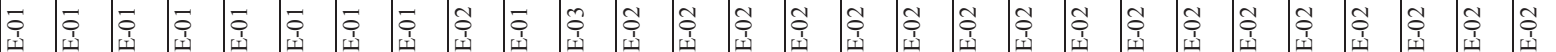

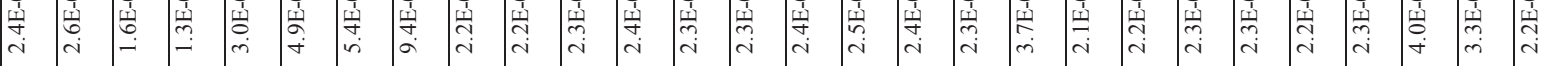

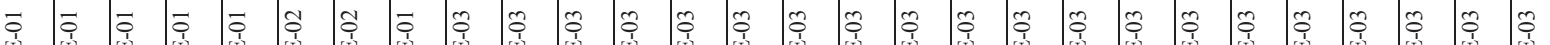

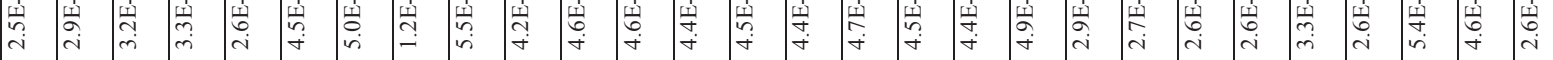

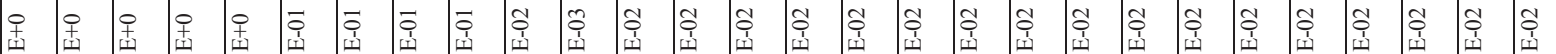

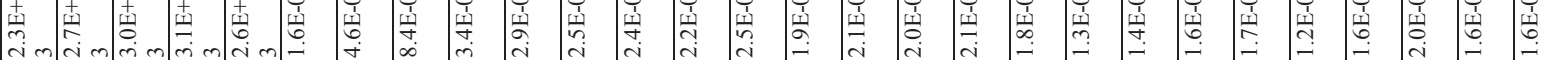
呆早

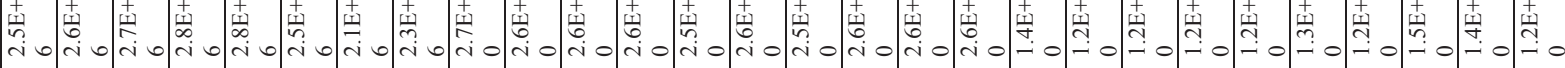

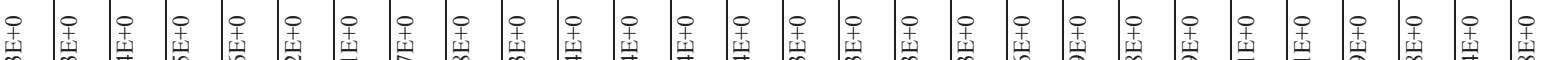

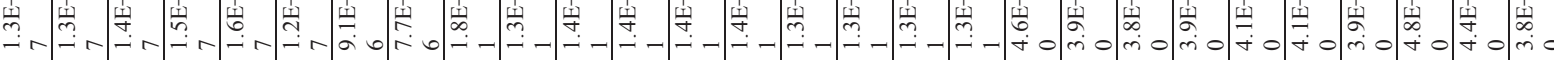
呈

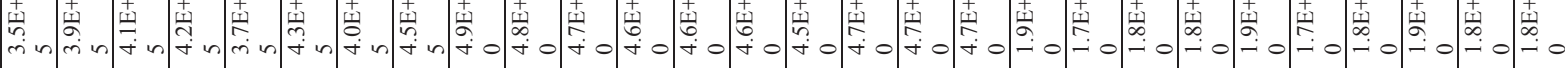

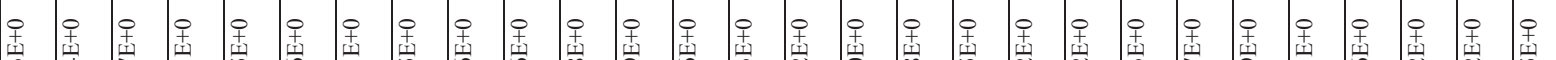

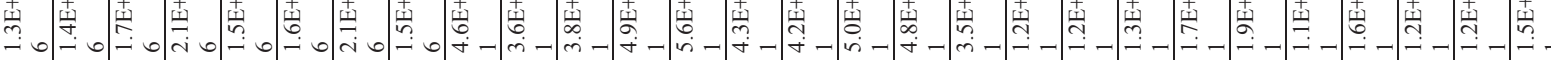

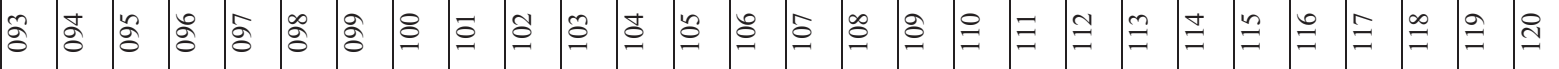




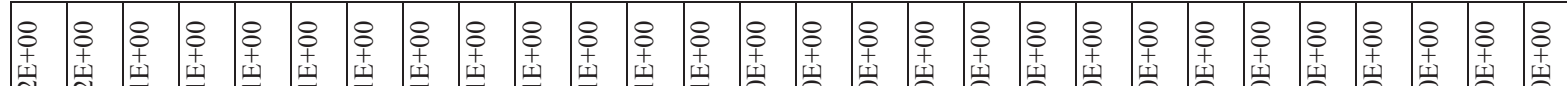

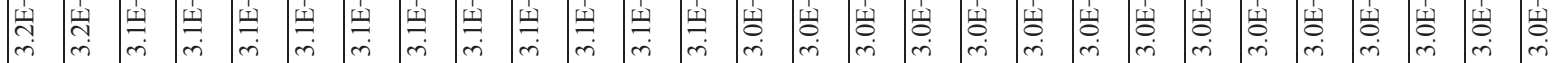

$\circ$

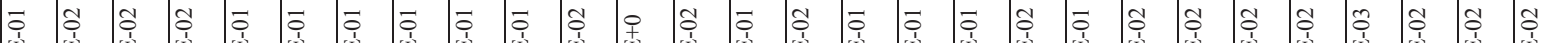

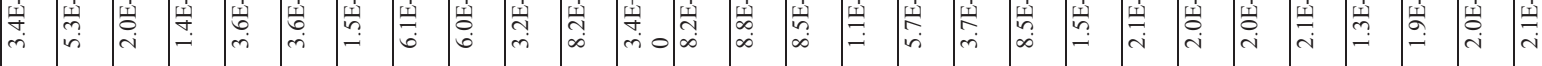

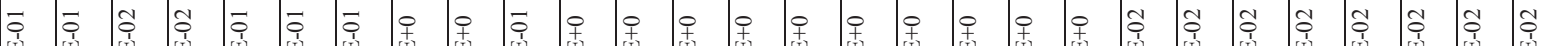

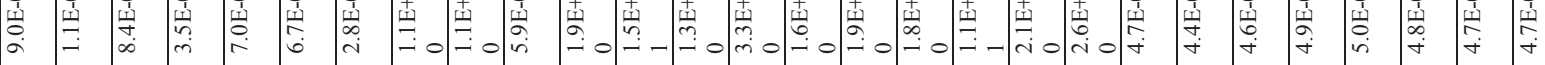

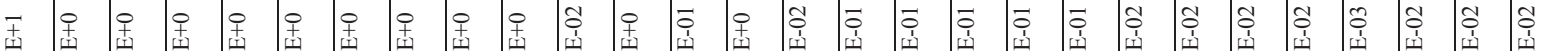

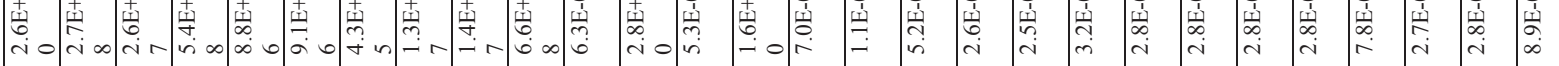

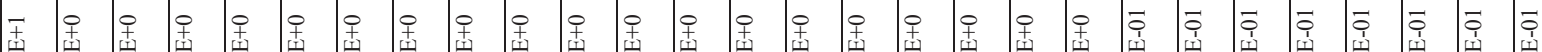

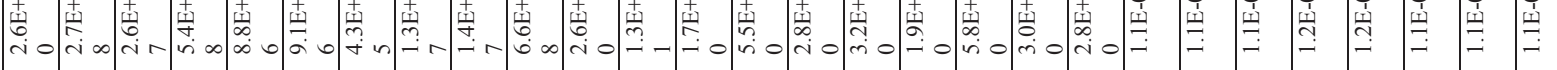

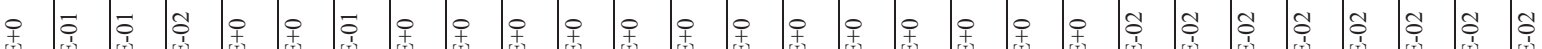

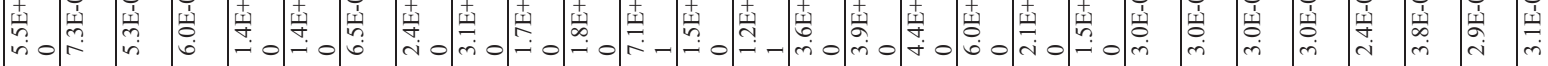

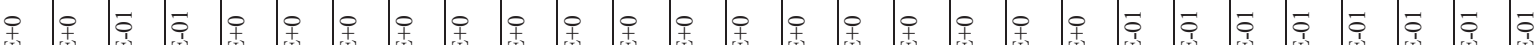

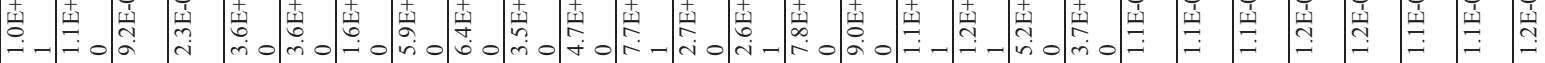

군 $\begin{aligned} & \text { f } \\ & \text { f }\end{aligned}$

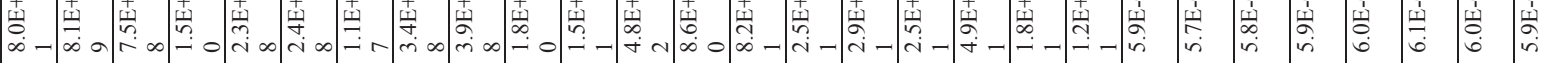

7 f

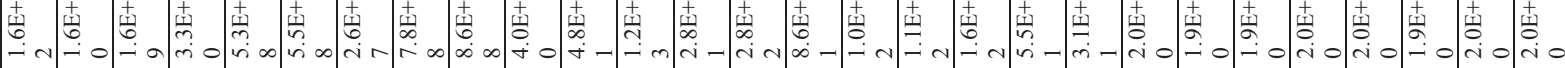

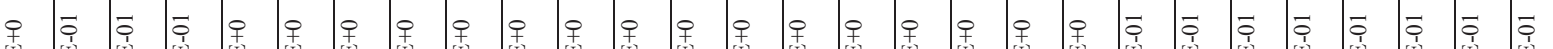

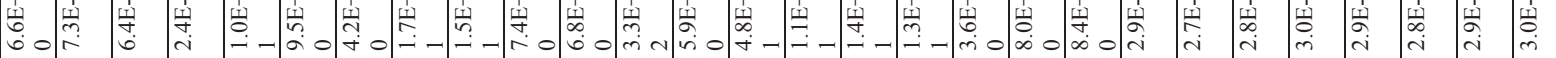

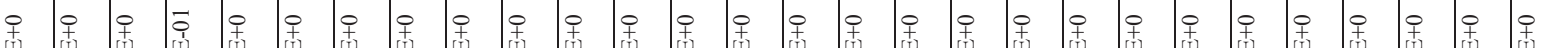

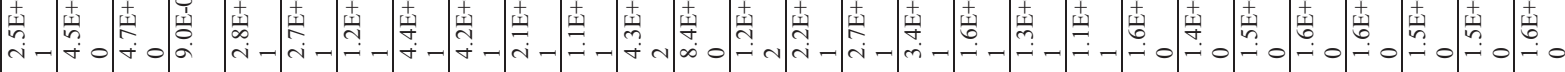

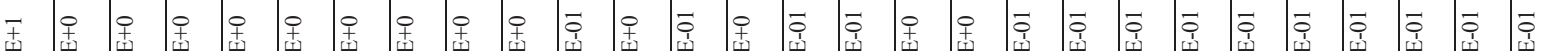

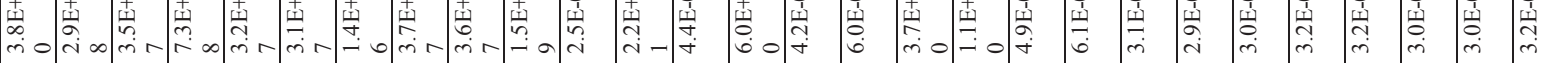

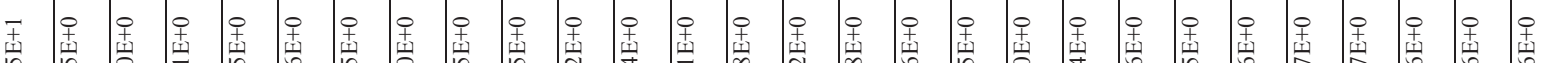

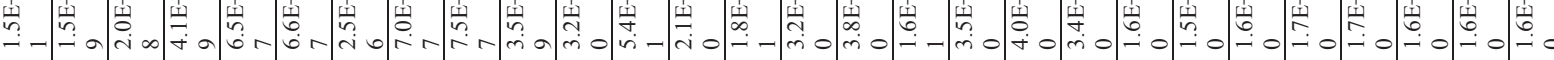

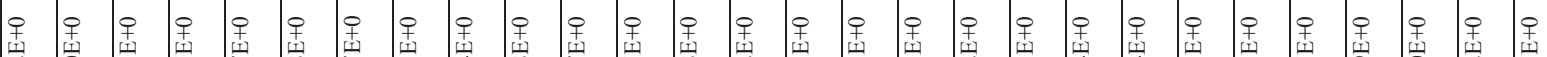

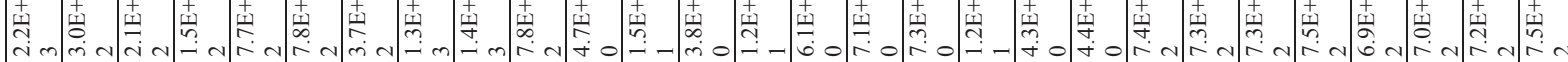

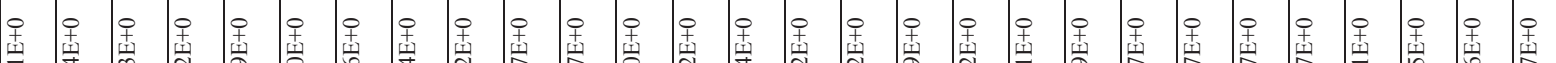

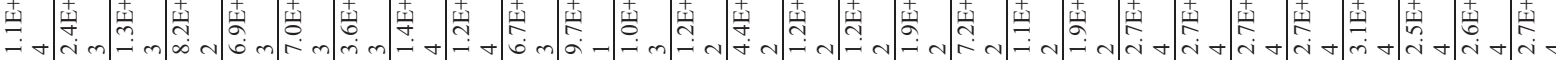

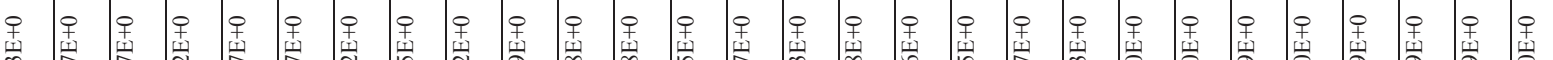

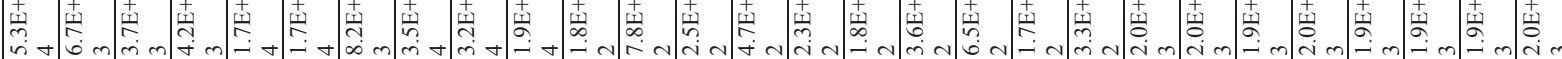
呆

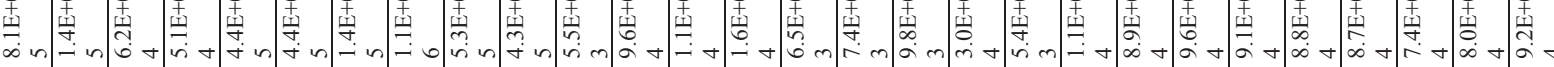

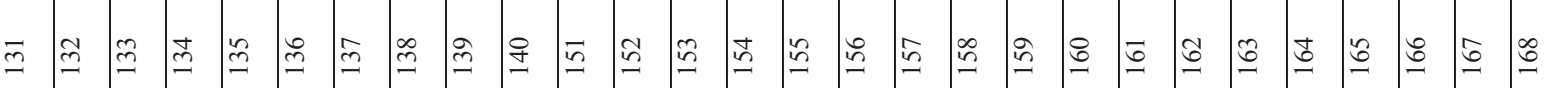




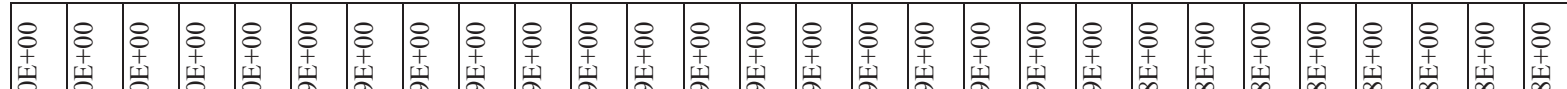

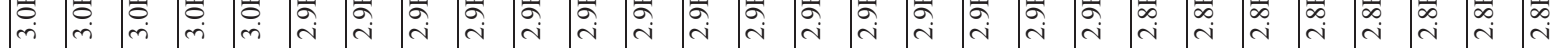

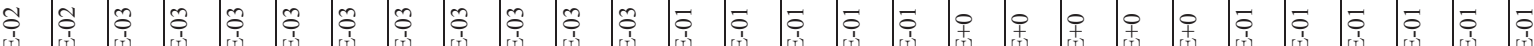

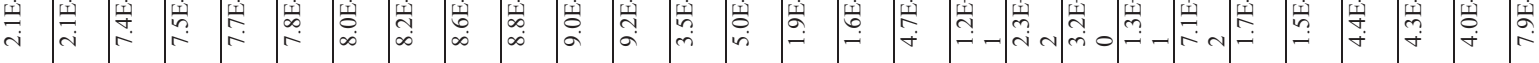

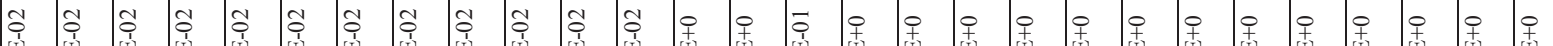

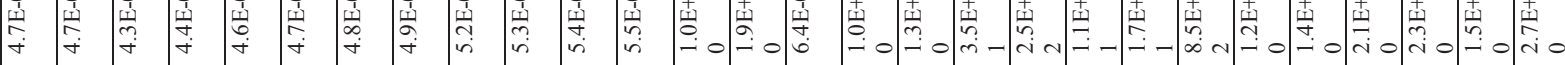

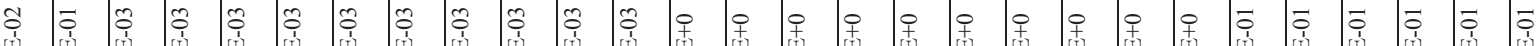

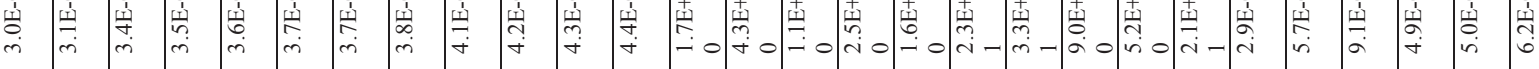

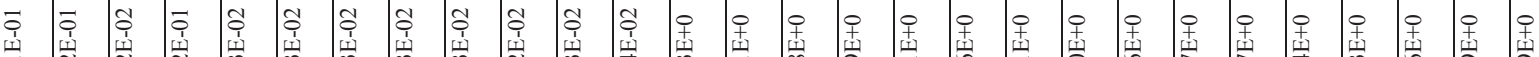

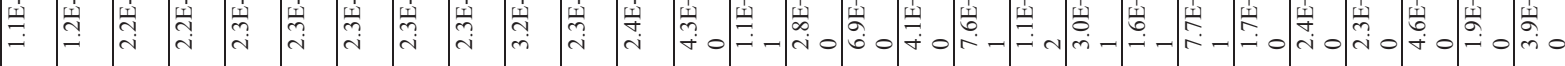

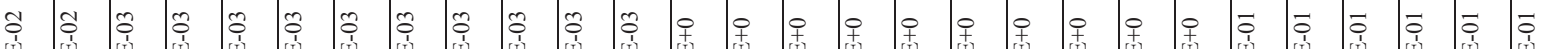

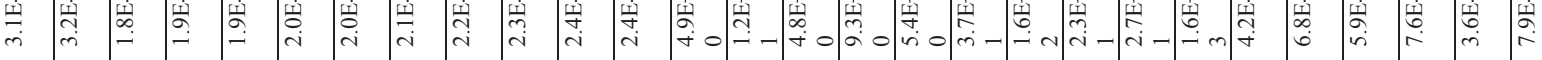

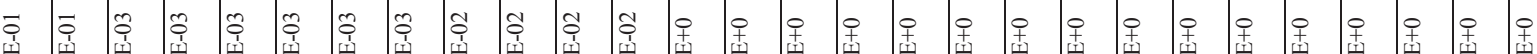

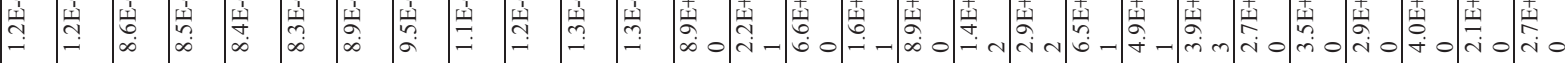

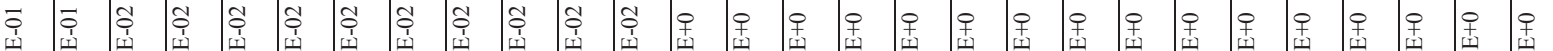

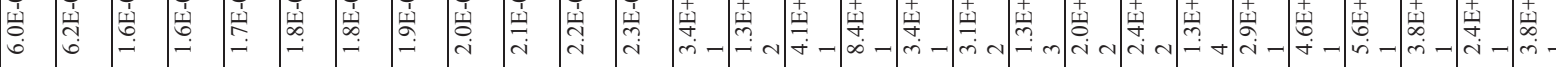

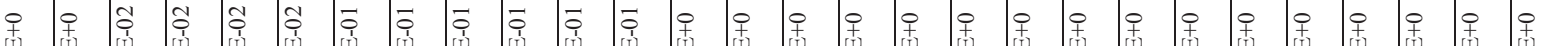

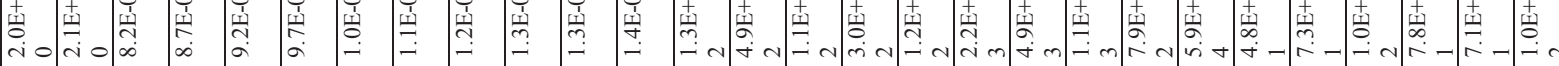

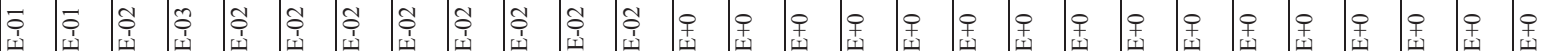

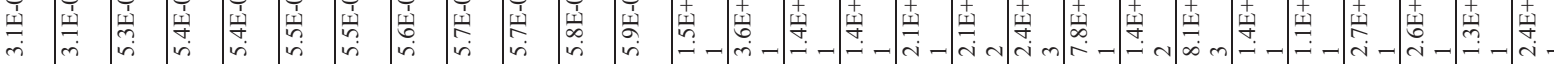

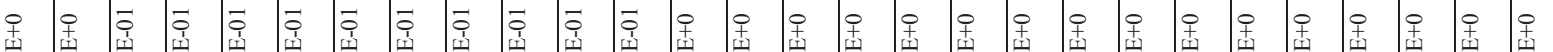

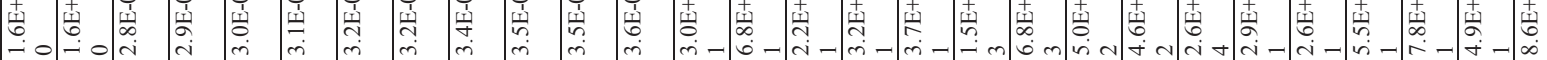

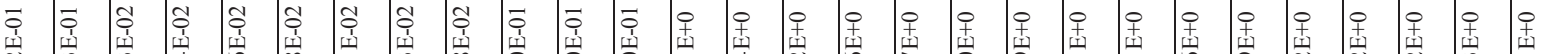

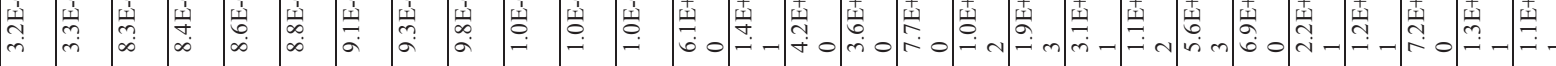

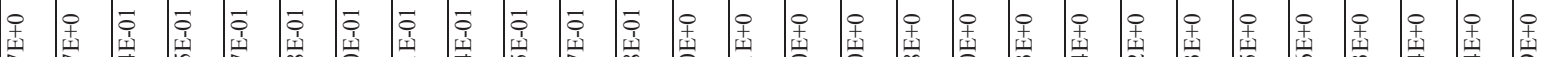

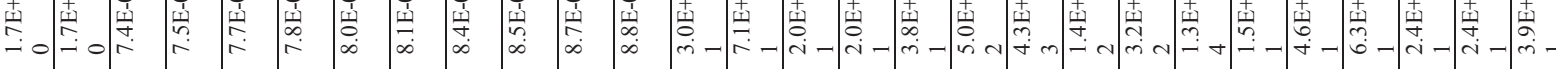

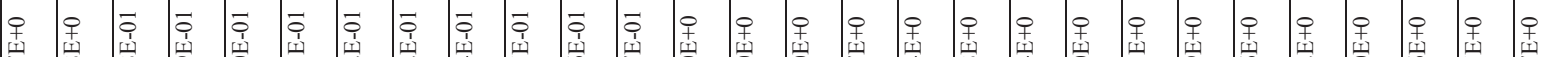

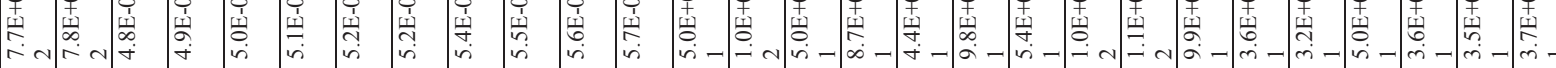

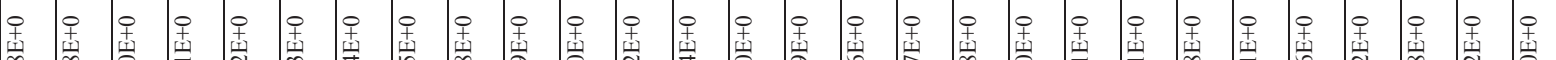

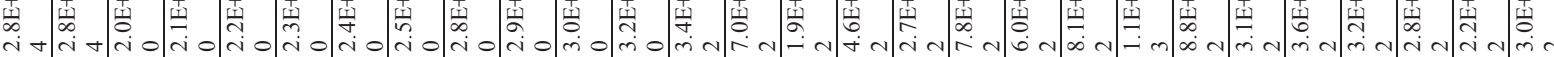

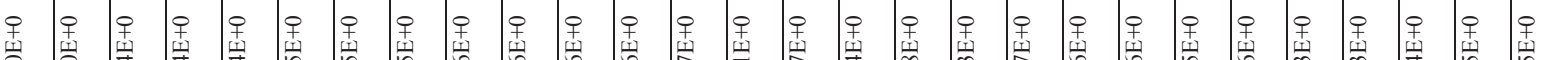

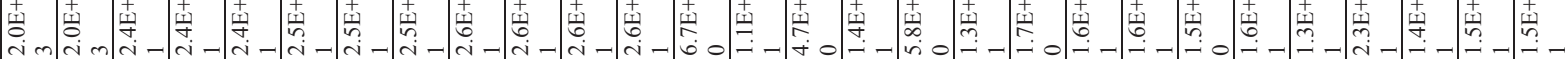

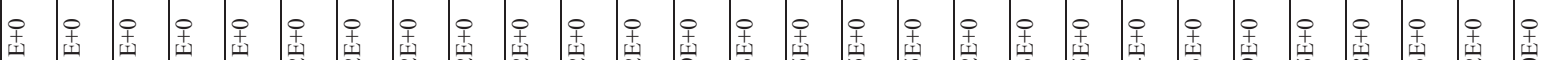

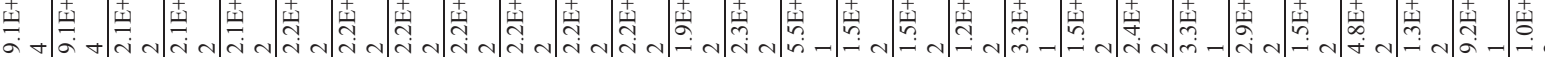
a 
\begin{tabular}{|l|l|l|l|l|l|l|l|l|l|l|l|l|l|l|l|l|l|l|l|l|l|l|l|l|l|l|}
\hline 8 & 8 & 8 & 8 & 8 & 8 & 8 & 8 & 8 & 8 & 8 & 8 & 8 & 8 & 8 & 8 & 8 & 8 & 8 & 8 & 8 & 8 & 8 & 8 & 8 & 8 & 8 \\
\hline
\end{tabular}

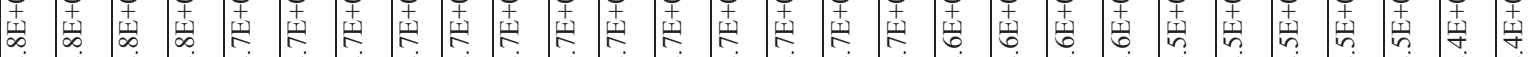

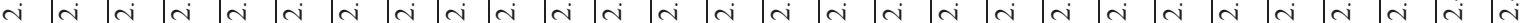

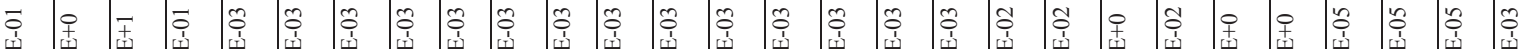

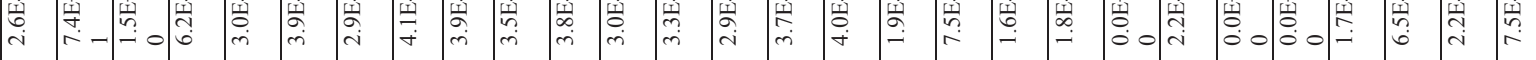

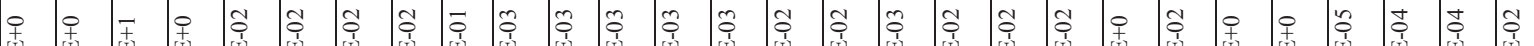

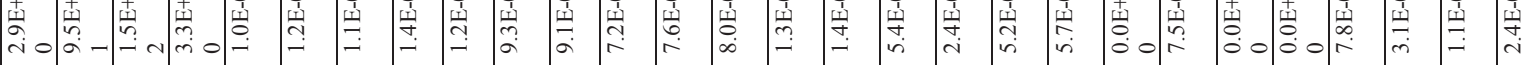

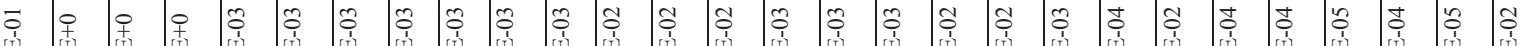

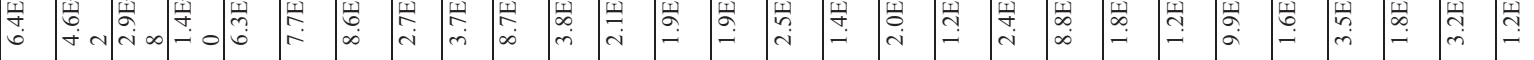

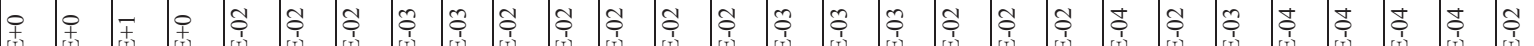

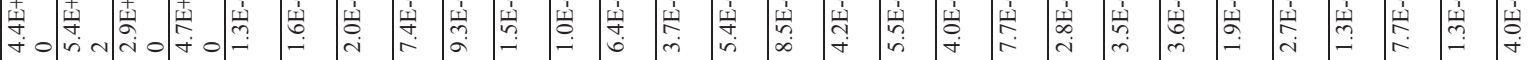

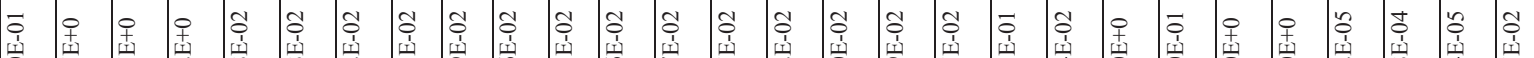

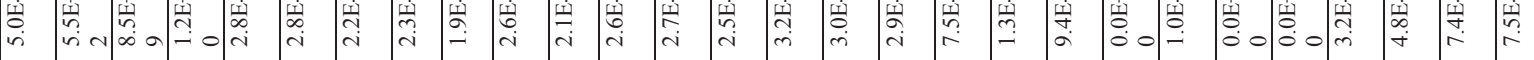

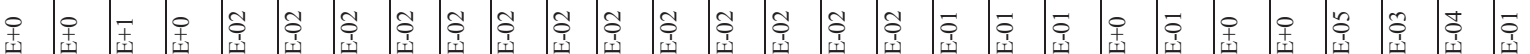

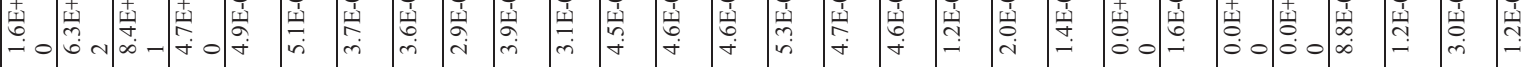
o d t

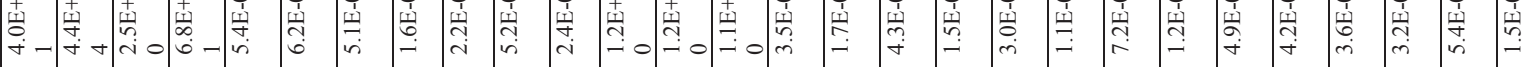

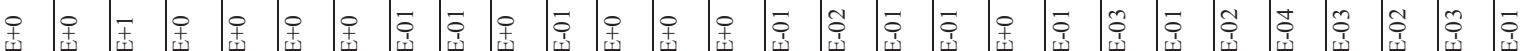

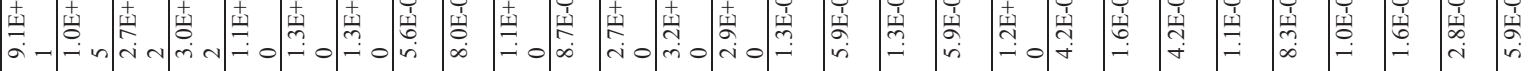

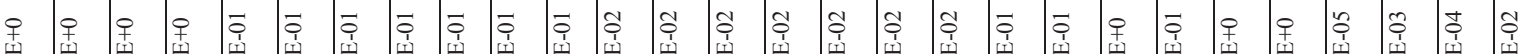

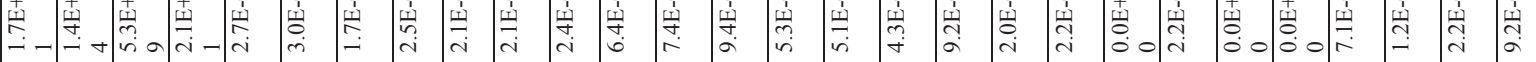

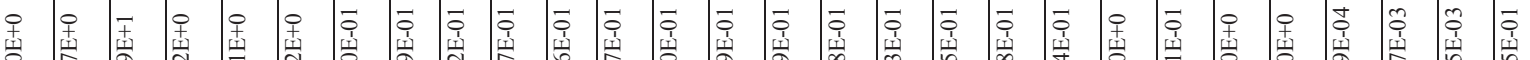

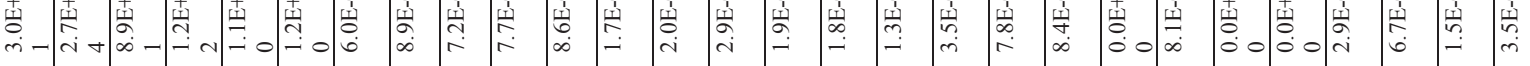

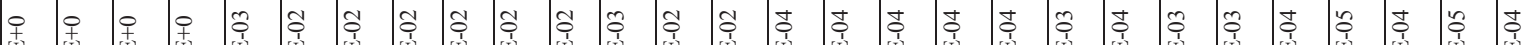

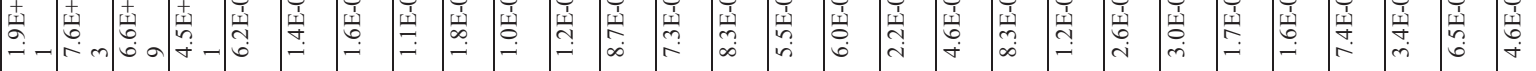

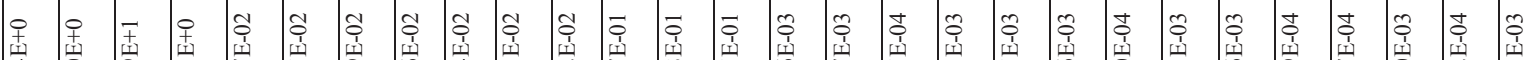

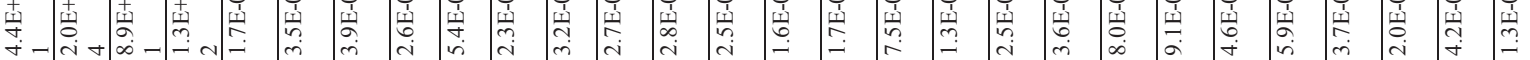

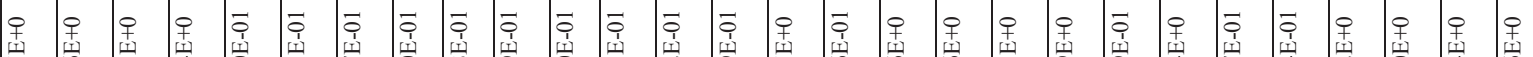

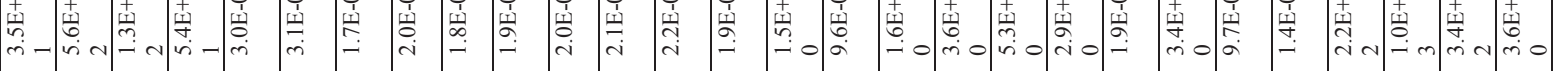

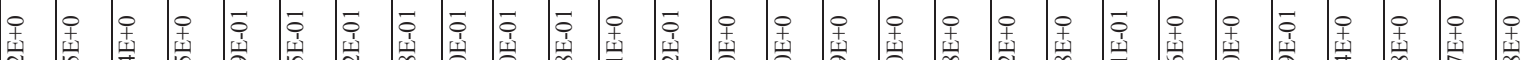

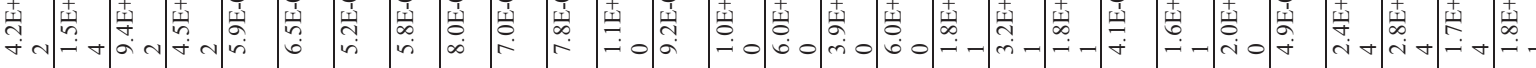

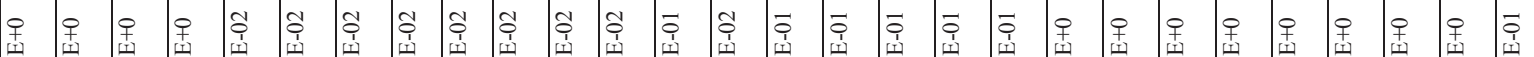

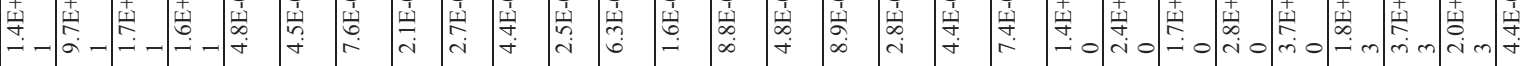
o d

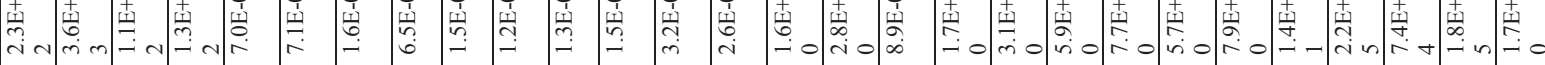

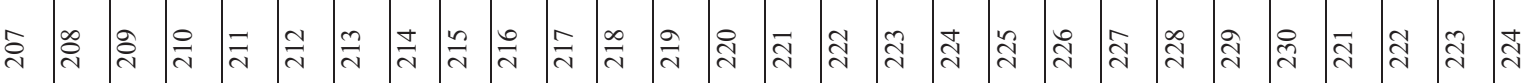




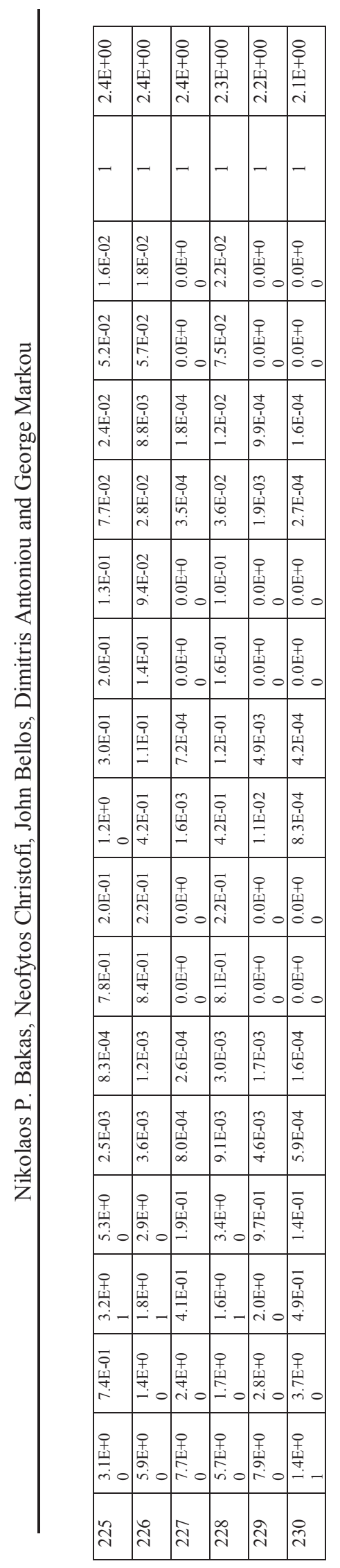

